\title{
Review on diagnosis and molecular characterization of Toxoplasma gondii in humans and animals
}

\author{
Uddin, A.H.M.M. ${ }^{19}$, Hossain, D. ${ }^{29}$, Ahsan, M.I. ${ }^{3}$, Atikuzzaman, M. ${ }^{1}$, Karim, M.R. ${ }^{4 *}$ \\ ${ }^{1}$ Department of Surgery and Theriogenology, Faculty of Veterinary, Animal and Biomedical Sciences, Sylhet Agricultural University, \\ Sylhet 3100, Bangladesh \\ 2Department of Medicine and Public Health, Faculty of Animal Science and Veterinary Medicine, Sher-e-Bangla Agricultural University, \\ Dhaka 1207, Bangladesh \\ ${ }^{3}$ Department of Epidemiology and Public Health, Faculty of Veterinary, Animal and Biomedical Sciences, Sylhet Agricultural University, \\ Sylhet 3100, Bangladesh \\ ${ }^{4}$ Department of Medicine, Faculty of Veterinary Medicine and Animal Science, Bangabandhu Sheikh Mujibur Rahman Agricultural University, Gazipur \\ 1706, Bangladesh \\ IThese authors contributed equally to this work \\ *Corresponding author: vet_robiul@bsmrau.edu.bd
}

\section{ARTICLE HISTORY}

Received: 21 June 2021

Revised: 19 August 2021

Accepted: 19 August 2021

Published: 31 December 2021

\begin{abstract}
Toxoplasma gondii is an obligate intracellular protozoon which causes toxoplasmosis, an important zoonotic disease that is endemic worldwide. Common sources of $T$. gondii infection in humans are food or water contaminated with oocysts and raw or undercooked meat with cysts. In animals, common sources of infection include feed, water, or litter contaminated with oocysts. The diagnosis and molecular characterization of $T$. gondii infection in humans and animals is crucial due to public and veterinary health importance. Various traditional and serological methods have been used in clinical practice for toxoplasmosis diagnosis, but interpreting the results remains a challenge. Several molecular techniques have also been used for the detection and genetic characterization of $T$. gondii, but primarily in research settings. In this paper, we review the techniques that are currently used for the diagnosis and genetic characterization of $T$. gondii in humans and animals, along with their advantages and disadvantages. The techniques reviewed have laid the groundwork for the future development of more effective and precise detection and characterization of $T$. gondii. These advances will contribute to a better understanding of epidemiology, prevention and control of toxoplasmosis. Thus, this review would be of particular interest to clinical physicians, veterinarians and researchers.
\end{abstract}

Keywords: Toxoplasma gondii; diagnosis; genetic characterization; humans; animals.

\section{INTRODUCTION}

Toxoplasma gondii is an important obligate intracellular apicomplexan zoonotic protozoa that causes toxoplasmosis in humans and other warm blooded animals worldwide (Wana et al., 2020a; Matta et al., 2021). Like other protozoan species, $T$. gondii has three infectious stages including oocysts, bradyzoites and tachyzoites (Waldman et al., 2020). This parasite follows both vertical and horizontal route of transmissions (Dubey et al., 1998). Vertical transmission mainly occurs transplacentally during pregnancy (Webster, 2010; Sun et al., 2013). Horizontal transmission occurs due to consumption of raw or undercooked meat and fish containing bradyzoites; consumption of water, milk, and vegetables contaminated with oocysts; or the transfusion and transplantation of blood and organs harbouring tachyzoites from clinically infected patients (Elsheikha et al., 2020). Felidae family (domestic cats) are the definitive hosts; although humans, livestocks, birds, and fish can all act as intermediate hosts (Wana et al., 2020b; Al-Malki, 2021). During the prepatent period of approximately 18 days, a single cat can shed more than 100 million oocysts (Retmanasari et al., 2017).

Approximately one-third of the human population is infected with $T$. gondii through either oral, and blood or congenital transmission (Abbas et al., 2020; Wana et al., 2020b). Most animals are infected by the ingestion of food and water contaminated with oocysts from cat feces (Figure 1). In adults, primary $T$. gondii infections are often asymptomatic or may produce a mild, flu-like illness. In less than $10 \%$ of infections, a mononucleosis-like syndrome occurs with headache, malaise, and fever. Some patients may also experience fatigue, lymphadenopathy or ocular toxoplasmosis (Elsheikha et al., 2020). Reactivation of a latent infection can cause fatal toxoplasmatic encephalitis, myocarditis, and/orpneumonitis in immunocompromised 


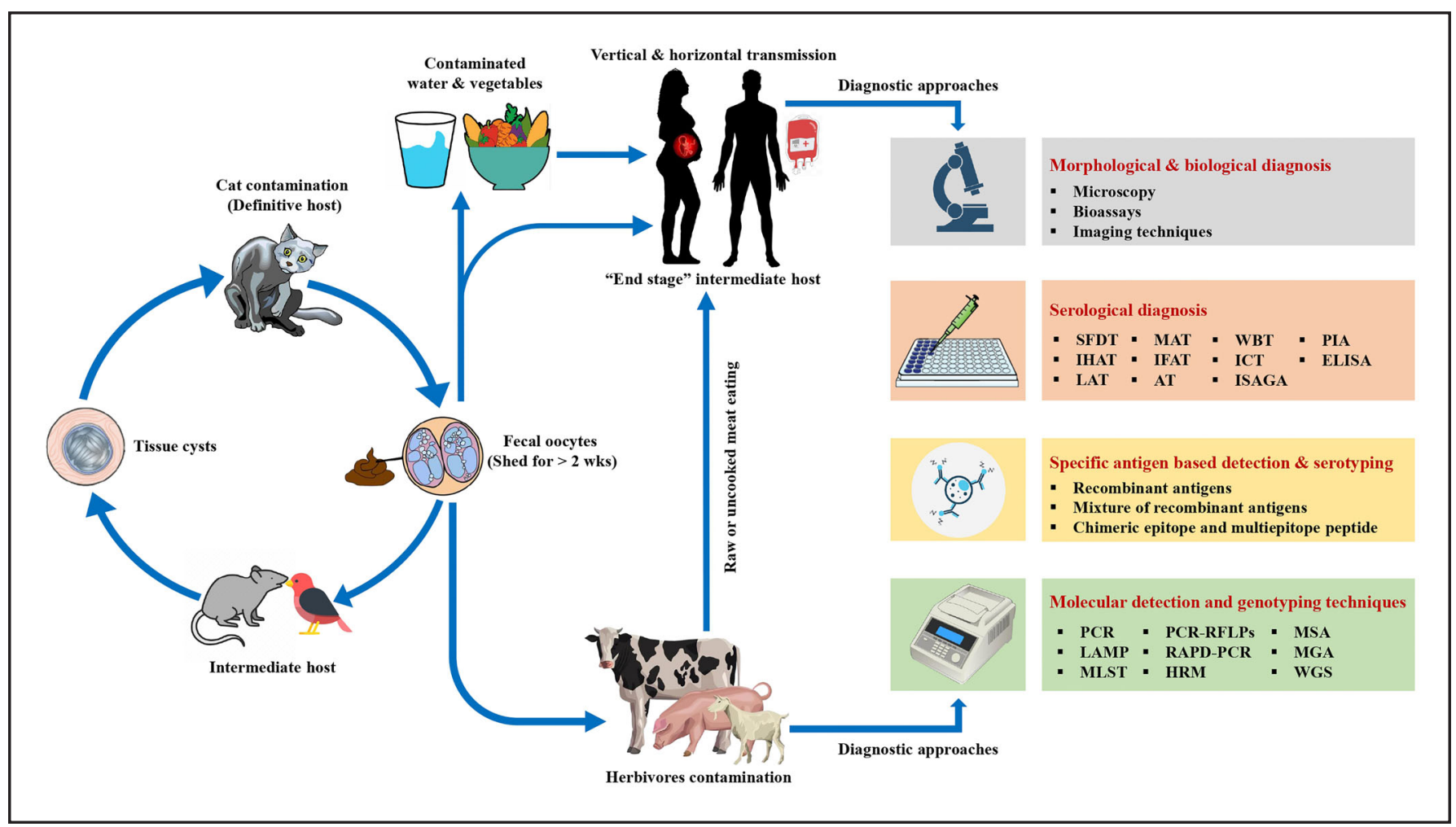

Figure 1. Transmission, life cycle and diagnostic approaches of Toxoplasma gondii in humans and animals. Abbreviations used: SFDT: Sabin-Feldman dye test, IHAT: Indirect hemagglutination test, LAT: Latex agglutination test, MAT: Modified agglutination test, IFAT: Indirect fluorescent antibody test, AT: Avidity test, WBT: Western blot test, ICT: Immunochromatographic test, ISAGA: Immunosorbent agglutination assay, PIA: Piezoelectric immunoagglutination assay, ELISA: Enzyme linked immunosorbent assay, PCR: Polymerase chain reaction, LAMP: Loop mediated isothermal amplification, MSA: Microsatellite analysis, MLST: Multilocus sequence typing, PCR-RFLPs: PCR-restriction fragment length polymorphisms, RAPD-PCR: Random amplified polymorphic DNAPCR, HRM: High-resolution melting, MGA: Metagenomics analysis, WGS: Whole-genome sequencing.

individuals (Smith et al., 2021). The most significant clinical signs of toxoplasmosis occur in pregnant individuals, as infection can lead to abortion, stillbirth, and fetal developmental disorders (Ferra et al., 2020a). If infection occurs early in a pregnancy, $T$. gondii can cause a variety of newborn complications including hydrocephalus, encephalitis, chorioretinitis, intracranial calcification, and mental retardation (Onduru \& Aboud, 2021).

According to numerous studies, the global prevalence of T. gondii is $30 \%$ in humans (Moncada \& Montoya, 2012), $14.0 \%$ in cattle (Retmanasari et al., 2017), 35.9\% in sheep (Andreoletti et al., 2007), $17.6 \%$ in goats (Calero-Bernal \& Gennari, 2019), 25.8\% in horses (Tassi, 2007), 6\% in pigs (Tenter et al., 2000), 6 to 88\% in dogs and cats (Calero-Bernal \& Gennari, 2019), and $12.8 \%$ in chickens (Calero-Bernal \& Gennari, 2019). However, the prevalence of $T$. gondii infections has been observed to differ from study to study, country to country, host to host, and so on. Variation among the human populations largely depends on geographical parameters (climate, relative humidity, temperature, rainfall, distance among villages, population density, and polyethnicity and monoethnicity (Dubey, 1993). T. gondii infection prevalence also differs based on age (Kodym, 2001) and gender (Jones et al., 2001). Similarly, the global distribution of $T$. gondii in different animal species depends on the geographical location (Shuralev et al., 2018), age (Cazarotto et al., 2016), gender (Djokic et al., 2016), herd and flock size (Herrero et al., 2016), mixture of animal species (Deksne et al., 2017), biosecurity and hygiene management (Tilahun et al., 2018), and disease and treatment parameters (Sun et al., 2015).
The diagnosis and genetic characterization of $T$. gondii is important for clinical management as well as epidemiological investigation, prevention, and control of toxoplasmosis in humans and animals (Liu et al., 2015; Gomes et al., 2020; Mohamed, 2020). Toxoplasmosis cannot be diagnosed based on clinical signs and symptoms alone (Tenter et al., 2000). However, parasite's latent form, during which it is not ordinarily found in blood circulation, makes the parasite challenging to isolate and diagnose (RobertGangneux \& Dardé, 2012). T. gondii diagnosis is usually made by biochemical, serological, histological, molecular tests, or by a combination of the above (Pal et al., 2014). Bioassays and serological tests are used to diagnose $T$. gondii infection in the laboratory environment (Liu et al., 2015). However, these tests are time consuming, laborious, expensive, health hazards, and require skilled personnel, all of which limits their routine use (Kotresha \& Noordin, 2010). Over the last two decades, consistent developments in serologic and molecular diagnostic methods with increased sensitivity and specificity have been a significant achievement in the detection of $T$. gondii infections (Ybañez et al., 2020). There is, however, no comprehensive review of the methods of $T$. gondii diagnosis and molecular characterization (Rostami et al., 2018; Ferra et al., 2020b). Such a review would help researchers and manufacturers in considering future research avenues for $T$. gondii diagnosis and genetic characterization. In this paper, we attempt to provide an updated and comprehensive review of the diagnosis and molecular characterization of $T$. gondii in humans and animals. 


\section{Literature search strategy}

Multiple science databases (Science Direct, Web of Science, PubMed, Scopus, and Google Scholar) were screened for literature on the diagnosis and genetic characterization of $T$. gondii. The following keywords, used alone or in combination: 'Toxoplasma gondii', 'toxoplasmosis', 'diagnosis', 'serodiagnosis', 'molecular diagnosis', 'genotyping', 'serotyping', 'humans' or 'animals'. Two authors independently undertook this searh, with studies screened via titles and abstracts followed by full-text review. After removing duplicates and irrelevant papers, reference lists of full-text articles were assessed for potentially useful citations not identified through the database search. The article screening was performed with Endnote software (version X9). Articles published up to April 30, 2021 were included in this review.

\section{Morphological and biological diagnosis}

\section{Microscopy}

Toxoplasma gondii can be identified using light microscopy in body fluids (cerebrospinal fluid, amniotic fluid, aqueous humour, bronchoalveolar lavage fluid and semen) (Liu et al., 2015), feces (Lilly \& Wortham, 2013), and biological specimens (brain tissues, lymph nodes and muscles) (McGovern \& Wilson, 2013). Haematoxylin and eosin (H\&E) and giemsa stains are usually used for microscopic identification of tachyzoites and bradyzoites. Periodic acid schiff (PAS) stain is commonly used for the identification of amylopection granules in bradyzoites (da Silva et al., 2010). However, Romanowsky stains also work well for the detection of tachyzoites in impression smears, and silver stain is a reliable option for detecting bradyzoites in tissue cysts. Electron microscopy has also been used to diagnose toxoplasmosis, although limitations of this technique include expense, low sensitivity, need for advanced training, and challenging regular operation (Liu et al., 2015).

\section{Bioassays}

Bioassays are the gold standard for the detection of $T$. gondii infection. They are performed by inoculating oocysts into an animal model and monitoring for infection (Hill et al., 2006). Murine and cat bioassays are commonly used for isolation and identification of $T$. gondii (Liu et al., 2015). Cat bioassays are considered standard because they are more powerful than murine bioassays (Rousseau et al., 2018). With cat bioassays, even low bradyzoites containing tissue samples, if fed, can lead to oocyst shedding in feces (Dubey, 2006). In the murine model bioassay; GKO mice (Opsteegh et al., 2016), C57BL/6 mice (Tyebji et al., 2020; Bergersen et al., 2021), WTBALB/c mice (Bergersen et al., 2021), SCID mice and Swiss Webster mice (Watson \& Davis, 2019) are used in various laboratories. To overcome the disadvantages of bioassays (expensive, time consuming, requires live parasite and a large number of mice), reserachers also developed serological and molecular methods to detect parasitic antigen or antibody and DNA directly from the samples (Opsteegh et al., 2020). Several researchers have suggested that bioassay methods do not meet animal ethical regulations (Rousseau et al., 2018), and that the use of bioassays in laboratories should be limited (Riaz et al., 2016).

\section{Imaging techniques}

Imaging techniques are include visual assessment of different organs, such as the brain and eye that facilitate toxoplasmosis diagnosis and can be monitored to assess therapeutic effect (Vutova et al., 2002). Computed tomography (CT) (Harrison \& Hulette, 2017), magnetic resonance imaging
(MRI) (Khalili et al., 2021), nuclear imaging (Rostami et al., 2019) and ultrasonography (US) (Rostami et al., 2019; De-laTorre \& Gómez-Marín, 2020) are commonly used for diagnosis of cerebral and ocular toxoplasmosis (Liu et al., 2015). Unfortunately, the results of imaging techniques are not yet satisfactory and this drives the researchers to explore more reliable imaging techniques (Rostami et al., 2018). CT scan is able to identify nodular lesions on the basal ganglion in central nervous system (CNS) toxoplasmosis. In congenital toxoplasmosis, cyst-like noduar calcified lesions develop in the periventriculus region and the choroid plexus and are appeared on CT scan (Masamed et al., 2009). MRI is most helpful for differentiation between various CNS lesions to determine the extent of CNS damage (Scheld et al., 2014). Prenatal US can also be used to identify brain lesions in congenital toxoplasmosis. Abdominal US can show hepatosplenomegaly and abdominal Iymphadenopathy, which occurs with some cases of toxoplasmosis (Lago et al., 2007). Recently, nuclear imaging tools, such as fluorodeoxyglucose positron-emission tomography (FDGPET), thallous chloride (201TI) and technetium-99m (99mTc) sestamibi (MIBI), have been developed and used to differentiate the CNS toxoplasmosis from CNS Iymphoma in HIV-positive patients (Rostami et al., 2018). Other advanced imaging techniques, such as fundus autofluorescence (FAF) (Lavinsky et al., 2012), confocal scanning laser ophthalmoscopy (CSLO) (Rostami et al., 2018), optical coherent tomography (OCT) (Lavinsky et al., 2012), fluorescent angiography (FA) (Rostami et al., 2018), ultrasound (Rostami et al., 2018), and indocyanine green angiography (ICG) (Lavinsky et al., 2012) are useful for the diagnosis and therapeutic management of ocular toxoplasmosis.

\section{Serological diagnosis}

\section{Sabin-Feldman dye test (SFDT)}

The Sabin-Feldman dye test was first developed by Sabin and Feldman (1948). The SFDT is performed by combining serum from the individual being tested with live tachyzoites (obtained from the peritoneal effusion of infected mice). This combination is then stained with methylene blue. If the serum contains anti-Toxoplasma antibodies, they will coat the tachyzoites and prevent them from taking up the stain (Reiter-Owona et al., 1999; Rorman et al., 2006). Although the SFDT has a high sensitivity and specificity, it is performed in very few laboratories due to the significant challenges associated with it (Udonsom et al., 2010). The test requires live tachyzoites (Udonsom et al., 2010), experienced technicians, and a sophisticated reference laboratory (Reiter-Owona et al., 1999).

\section{Indirect hemagglutination test (IHAT)}

Indirect hemagglutination test (IHAT) for diagnosis of toxoplasmosis was first proposed by Boyden (1951), and Stavitsky and Jarchow (1954) and later developed by Jacobs and Lunde (1957). The test uses sheep red blood cells (RBCs) to detect antigens of $T$. gondii infections. Agglutination of RBCs by Toxoplasma gondii antigens indicates a positive result, and lack of agglutination indicates a negative result (Su et al., 2010; Webster, 2010). IHAT is safe, rapid, and easy to perform (Caruana, 1980). Despite these advantages, IHAT has a low sensitivity and hence is not recommended for the diagnosis of $T$. gondii infection in chickens (Yan et al., 2010).

\section{Latex agglunination test (LAT)}

The latex agglunination test (LAT) detects $T$. gondii antibodies (IgG and IgM). Tachyzoites are inoculated into either cell 
cultures or mice to stimulate antigen production. Antigens are then detected by commercial antigen kits (Jiang et al., 2008). The microneme protein 3 (MIC3) based latex agglutination test, a derivative of the traditional LAT, is considered to be more reliable for toxoplasmosis serodiagnosis (Jiang et al., 2008). The MIC3 surface protein is expressed in multiple stages of $T$. gondii (tachyzoites, bradyzoites and sporozoites). It facilitates attachment between host cell receptors and parasite surface proteins (Garcia-Réguet et al., 2000). Mice (Ismael et al., 2003) and human sera (Garcia-Réguet et al., 2000) detected by T. gondii microneme proteins, are used as antigens (Sager et al., 2003; Pietkiewicz et al., 2004).

\section{Modified agglutination test (MAT)}

The modified agglutination test (MAT) was first developed by Fulton and Turk (1959). It was later modified by several researchers for the detection of $T$. gondii antibodies in humans (Su et al., 2010; Al-Adhami et al., 2016) and animals (Dubey \& Desmonts, 1987). The test is more specific, rapid, and cost effective than other serological tests (Webster, 2010). Tachyzoites, produced by intraperitoneal inoculation in mice, are used for MAT. Positive results are confirmed by agglutination of the tachyzoites (Fernandes et al., 2019). 2mercaptoethanol, alkaline buffer, Evan's blue dye, and TgMAT antigen are added to the antigen mixture, which diminishes the IgM antibodies in serum samples (Dubey, 1997).

\section{Indirect fluorescent antibody test (IFAT)}

Indirect fluorescent antibody test (IFAT) is an easy and reliable test for $T$. gondii (Rorman et al., 2006). It was first described by Camargo (1964). The test is a two-step immunologic reaction. First, tachyzoites bind with antiToxoplasma immunoglobulins in a patient's serum. Second, the bound complex is identified by a fluorescein labelled anti-whole globulin. The reaction is examined by fluorescence microscopy and the result is expressed in IU/ $\mathrm{mL}$ as recommended by World Heath Organization (WHO). Fluorescence indicates a positive result, while lack of it indicates a negative result. If serum contains rheumatoid factors or antinuclear antibodies, there is a high chance of false-positive results. So caution must be taken when interpretting IFAT results (Rorman et al., 2006).

\section{Enzyme linked immunosorbent assay (ELISA)}

Enzyme linked immunosorbent assay (ELISA) is a widely used diagnostic tool for the detection of antigenic markers and active antibodies with satisfactory sensitivity and specificity (Liu et al., 2015). There are three basic components of an ELISA: a solid phase antigen or antibody, an enzyme-coated antigen or antibody, and a substrate for the enzymatic reaction (Liu et al., 2015). Different types of ELISA tests, including indirect ELISA and sandwich ELISA, can be used in the serodiagnosis of $T$. gondii. Indirect ELISA is performed using a microtitre plate to which the antigen of interest directly adheres, while sandwich ELISA uses antibodies already adhered to the plate to bind the antigen of interest. The antigen is then identified by a primary antibody to which an enzyme-conjugated secondary antibody binds. A substrate is added, allowing the enzyme to create a color reaction. IgG, IgM and IgA anti-Toxoplasma antibodies are frequently identified using ELISA. Tachyzoites lysate antigen (TLA) is typically used for indirect ELISA diagnosis to $T$. gondii infections (Liu et al., 2015). However, due to lack of standardization, the results of TLA-based ELISA are contradictory among different laboratories, experiments, and batches. Recently, a number of recombinant antigens have been identified: surface antigens SAG1 (Burg et al., 1988; Kotresha et al., 2012) and SAG2 (Hiszczyñska-Sawicka et al., 2005); matrix protein (MAG1) (Holec et al., 2007); microneme proteins MIC2 (Beghetto et al., 2006), MIC3 (Beghetto et al., 2003), MIC4 (Sardinha-Silva et al., 2019), and MIC5 (Saouros et al., 2012); rhoptry proteins ROP1 (Holec-Gasior et al., 2009) and ROP2 (Aubert et al., 2000); and granule antigens GRA1 (Hiszczyñska-Sawicka et al., 2003; Pietkiewicz et al., 2004), GRA2 (Holec-Gasior et al., 2009; Lau et al., 2012; Ching et al., 2013), GRA4 (Lau et al., 2010a; Hanafiah et al., 2020), GRA6 (Redlich \& Müller, 1998; Hiszczyñska-Sawicka et al., 2005), GRA7 (Hiszczyñska-Sawicka et al., 2003; Selseleh et al., 2012), GRA8 (Hiszczyñska-Sawicka et al., 2003) and GRA9 (Nockemann et al., 1998). These recombinant antigens have higher sensitivity and specificity for T. gondii diagnosis (Aubert et al., 2000; Li et al., 2000). The sandwich ELISA with TLA and recombinant P35 is commonly used for the detection of human IgM antibodies and acute infection (Suzuki et al., 2000; Lu et al., 2006). With all ELISA tests, positive or negative results are determined by the correlation between the optical densities of the control serum. The modified ELISA, also called the dot-ELISA, is more sensitive, specific, easier to perform, as it does not require sophisticated equipment.

\section{Immunosorbent agglutination assay (ISAGA)}

The immunosorbent agglutination assay (ISAGA) is the most precise test for detecting IgM, IgA, and IgE antibodies against T. gondii (Stepick-Biek et al., 1990). Toxoplasma gondii tachyzoites are used as the antigen for this test. This test is named based on the antibody that it identifies, such as IgM-ISAGA, IgA-ISAGA, and IgE-ISAGA (Desmonts \& Thulliez, 1985; StepickBiek et al., 1990). IgM-ISAGA is used for the diagnosis of acute and congenital toxoplasmosis (Desmonts \& Thulliez, 1985). IgE-ISAGA is used for the diagnosis of acute toxoplasmosis (Pinon et al., 1990), toxoplasmic encephalitis and chorioretinitis (Remington et al., 2004). IgA-ISAGA is used for the diagnosis of prenatal, neonatal, and postnatal congenital toxoplasmosis (Stepick-Biek et al., 1990).

\section{Immunochromatographic test (ICT)}

Immunochromatographic test (ICT) is a rapid, easy, and costeffective assay with high sensitivity and specificity. ICT identifies target antigens (or sometimes antibodies) from serum or blood samples. ICT uses colloidal gold-labeled antibody (CGLA) dipped on a nitrocellulose membrane as a test surface. CGLA binds with the target antigen (mobile phase), then progresses through an immobile phase using capillary flow, and, finally, antibody-antigen complexes show a color reaction (Wang et al., 2011). Sensitivity and specificity of this test have been reported as $100 \%$ in the USA, and $97 \%$ and $96 \%$, in France (Begeman et al., 2017). Due to high sensitivity and specificity, ICT is an important tool for diagnosing toxoplasmosis in humans (Wassef \& AbdelMalek, 2019) and animals (Khan \& Noordin, 2020). A modified ICT, based on recombinant TgGRA7, has been developed for rapid detection of $T$. gondii in the field setting (Terkawi et al., 2013). A dynamic flow immunochromatographic test (DFICT) has also been developed for the rapid detection of $T$. gondii infection in dogs and cats (Jiang et al., 2015). This test combines techniques from immunochromatography and fluid dynamics. DFICT is attractive due to its efficiency, low sample volume requirements, and high selectivity. A list of ICTs used for the diagnosis of $T$. gondii infections in humans and animals is presented in Table 1. 
Table 1. Summary of immunochromatographic (ICT) tests used for diagnosis of toxoplasmosis in humans and animals

\begin{tabular}{|c|c|c|c|c|c|}
\hline $\begin{array}{l}\text { Antigen/ } \\
\text { antibody }\end{array}$ & $\begin{array}{l}\text { Target } \\
\text { molecules }\end{array}$ & Reference test & Host & Results & References \\
\hline Whole-cell lysate & $\begin{array}{l}>\lg G \\
>\lg M\end{array}$ & $\begin{array}{l}>\text { SFDT } \\
>\text { IgM ELISA }\end{array}$ & Human & $\begin{array}{l}\text { Sensitivity: } 100 \% \\
\text { Specificity: } 100 \%\end{array}$ & (Begeman et al., 2017) \\
\hline $\begin{array}{l}\text { Recombinant } \\
\text { antigen }\end{array}$ & $\begin{array}{l}>\lg G \\
>\lg M\end{array}$ & $\begin{array}{l}>\text { SFDT } \\
>\text { IgM ELISA }\end{array}$ & Human & $\begin{array}{l}\text { IgG-Sensitivity: } 100 \% \\
\text { IgG-Specificity: } 96.3 \% \\
\text { IgM-Sensitivity: } 62.2 \% \\
\text { IgM-Specificity: } 88.5 \%\end{array}$ & (Gomez et al., 2018) \\
\hline $\begin{array}{l}\text { Recombinant } \\
\text { antigen }\end{array}$ & $\begin{array}{l}>\lg G \\
>\lg M\end{array}$ & $\begin{array}{l}>\text { SFDT } \\
>\text { IgM ELISA }\end{array}$ & Human & $\begin{array}{l}\text { IgG-Sensitivity: } 100 \% \\
\text { IgG-Specificity: } 97.5 \% \\
\text { IgM-Sensitivity: } 28 \% \\
\text { IgM-Specificity: } 97.6 \%\end{array}$ & (Gomez et al., 2018) \\
\hline $\begin{array}{l}\text { N-terminal rSAG1A } \\
+ \text { GRA2 }\end{array}$ & $>\lg G$ & $>$ ELISA & Human & $\begin{array}{l}\text { Sensitivity: } 97.1 \% \\
\text { Specificity: } 100 \%\end{array}$ & (Song et al., 2013) \\
\hline rSAG1 & $>\lg G$ & $>$ ELISA & Cat & $\begin{array}{l}\text { Sensitivity: } 100 \% \\
\text { Specificity: } 99.4 \%\end{array}$ & (Chong et al., 2011) \\
\hline rtSAG2 & $>\lg G$ & $\begin{array}{l}>\text { ELISA } \\
>\text { LAT }\end{array}$ & Cat & $\begin{array}{l}\text { ELISA-Sensitivity:97.2\% } \\
\text { ELISA-Specificity: } 95.8 \% \\
\text { LAT-Sensitivity: } 100 \% \\
\text { LAT-Specificity: } 94.5 \%\end{array}$ & (Huang et al., 2004) \\
\hline SAG3 & $>\lg G$ & $>E$ ELISA & Pig & $\begin{array}{l}\text { Sensitivity: } 100 \% \\
\text { Specificity: } 99.65 \%\end{array}$ & (Luo et al., 2018) \\
\hline
\end{tabular}

\section{Western blot (WB)}

In Western blot, gel electrophoresis (12\% polyacrylamide gel) is used to separate serum proteins according to their molecular weight. A primary antibody is added which binds to the protein of interest. Then, a second antibody, conjugated with an enzyme, is added which binds to the primary antibody and facilitates identification of the protein of interest. For toxoplasmosis diagnosis, the proteins of interest are $T$. gondii antibodies (Meek et al., 2003). Western blot is useful for the diagnosis of acute and congenital toxoplasmosis because of its ability to detect low antibody levels (Sardinha-Silva et al., 2019).

\section{Piezoelectric immunoagglutination assay (PIA)}

Piezoelectric immunoagglutination assay is a new development in serodiagnosis of $T$. gondii infection. It is based on the LAT principle (Wang et al., 2004). For this method, a piezoelectric quartz crystal (PQC) is responsible for the bio-molecular interaction and quantification. Gold nanoparticles are substituted for latex particles to make the test easier, more reliable, and more sensitive for toxoplasmosis diagnosis. The agglutination properties of gold nanoparticle suspensions create large variations in absorption spectrum and are used to develop agglutination based diagnostic methods. The agglutination complex of antigen-coated gold nanoparticles and antibodies is viewed by transmission electron microscopy (TEM). PIA can be used to detect Toxoplasma antibody in both blood and serum samples (Wang et al., 2004).

\section{Avidity test}

The term avidity indicates 'functional affinity', which is the binding potency of antigens and antibodies (Hedman et al., 1993). This test is performed by different serological procedures, such as enzyme linked immunosorbent assay (ELISA) and Western blot (WB) (Liu et al., 2015). The results of avidity tests are low during the early stage of infection and higher with progression of infection. Thus, the avidity test can distinguish acute and chronic infection of $T$. gondii (de Ory et al., 1995). However, there are limitations to the avidity test. Toxoplasma gondii-specific low-avidity IgG antibodies may persist for months pregnant women and treatment of $T$. gondii may delay the avidity maturation during pregnancy (Meroni et al., 2009). High concentrations of antibodies in serum samples may also affect the results of avidity testing. It is necessary to improve detection methods of antibody avidity (Bonyadi \& Bastani, 2013).

\section{Specific antigen-based detection and serotyping}

\section{Recombinant antigens}

Recombinant antigens are developed based on specific proteins from $T$. gondii that have been encoded, cloned, and expressed by different expression systems. Many of these proteins were originally identified as antibodies in human and animal serum samples (Rostami et al., 2018; Ferra et al., 2020a). The antigens include surface antigens SAG1 (P30) (Kotresha et al., 2012; Bachan et al., 2018), SAG2 (P22) (Singh et al., 2014; Sudan et al., 2019), and SAG3 (P43) (Khanaliha et al., 2012); dense granule antigens GRA1 (P24) (HiszczyñskaSawicka et al., 2003), GRA2 (P28) (Holec-Gasior et al., 2009; Lau et al., 2012; Ching et al., 2013), GRA4 (Lau et al., 2010a), GRA5 (Holec-Gasior \& Kur, 2010), GRA6 (P32) (Redlich \& Müller, 1998; Hiszczyñska-Sawicka et al., 2005), GRA7 (P29) (Selseleh et al., 2012; Wang et al., 2014a; Cai et al., 2015), GRA8 (P35) (Aubert et al., 2000; Hiszczyñska-Sawicka et al., 2005; Lu et al., 2006; Duong et al., 2020), and GRA9 (B10/P41) (Nockemann et al., 1998); the rhoptry antigens ROP1 (P66) (Aubert et al., 2000; Holec-Gasior et al., 2009), ROP2 (P54) (Nigro et al., 2003), ROP5 (Grzybowski et al., 2015), ROP8 (Sonaimuthu et al., 2014) and ROP18 (Grzybowski et al., 2015); the matrix antigen MAG1 (Holec et al., 2007; Zhuo et al., 2017); M2AP (Beghetto et al., 2006); and the micronene protein MIC1 (Holec et al., 2008) (Table 2). In earlier studies, TLA was a commonly used antigen in the serodiagnosis of T. gondii (Holec-Gasior, 2013). However, several limitations of TLA (high expense, time-consuming to make and health hazards for laboratory personel) restrict its current use. Nonetheless, the recombinant antigen-based diagnosis of toxoplasmosis mazimizes output. It is also easy to handle and able to differentiate disease phases that accelerate the diagnosis and treatment. 


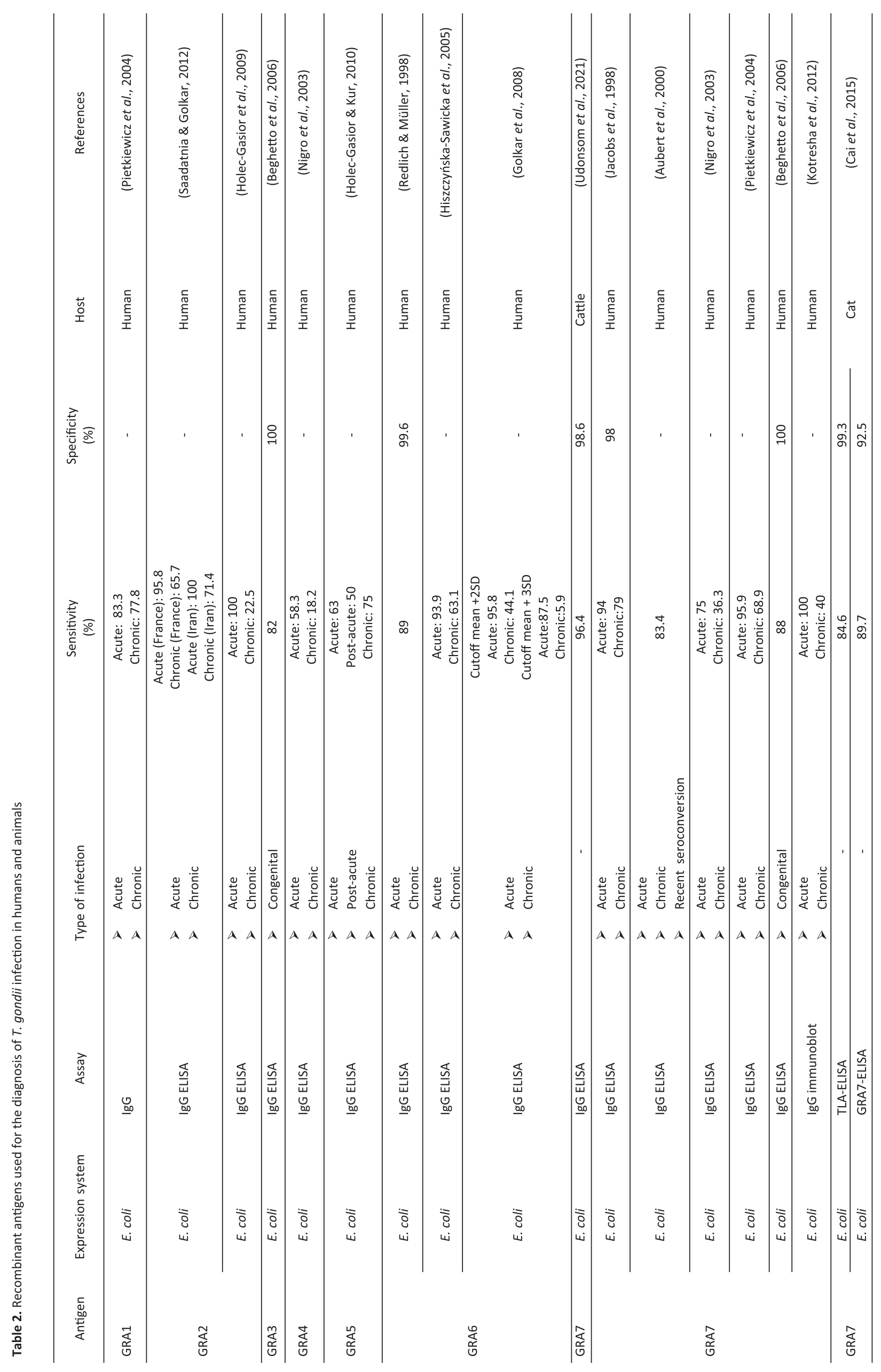




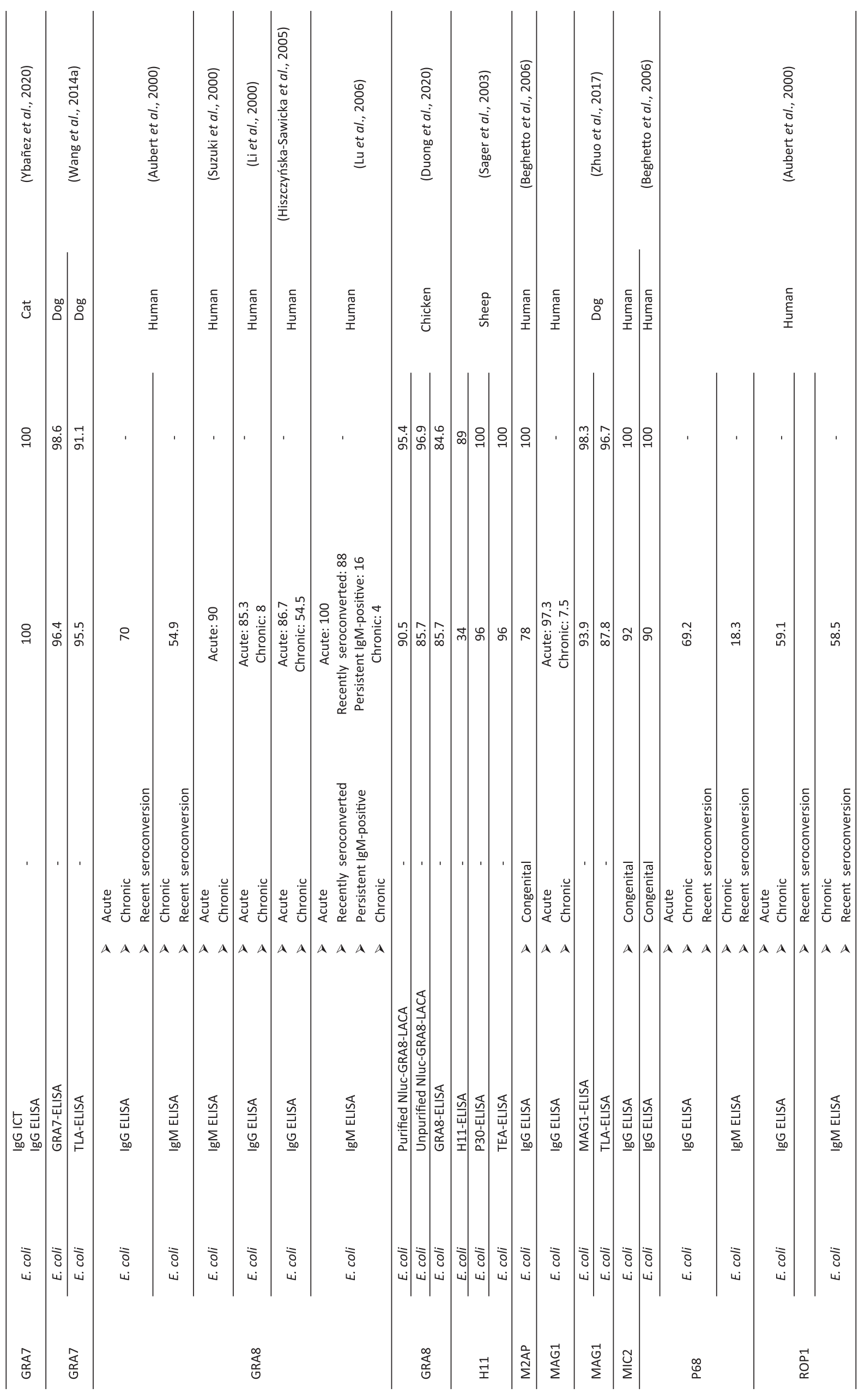




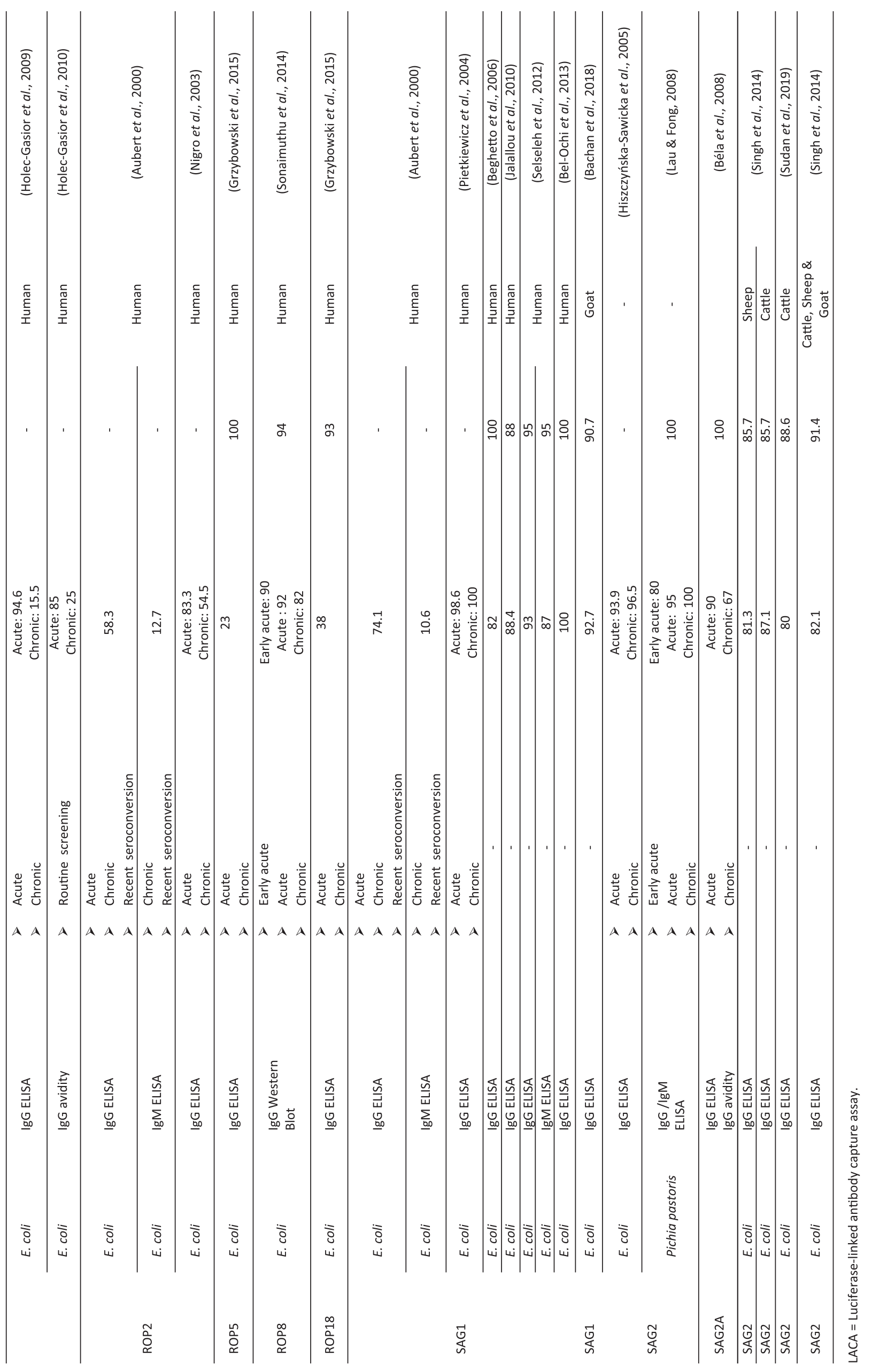




\section{Mixture of recombinant antigens}

Use of a recombinant antigen mixture in the serodiagnosis of $T$. gondii showed better performance than use of a single recombinant antigen (Jacobs et al., 1999). Johnson et al. (1992) reported that the mixture of recombinant proteins $\mathrm{H} 4 / \mathrm{GST}$ and H11/GST showed higher sensitivity (81.3\%) than individual tests of H4/GST (54\%) and H11/GST (61\%) in IgM ELISA. Similarly, GRA7 and Tg34AR antigens separately had a sensitivity of $81 \%$ and $88 \%$ respectively. However, a mixture of these two antigens had a $96 \%$ sensitivity (Jacobs et al., 1999). At present, many recombinant protein mixtures are used in research and laboratories for the detection of $T$. gondii in humans and animals (Table 3 ).

\section{Chimeric epitope and multiepitope peptide}

Recently, chimeric antigens have been considered as a new diagnostic strategy for the detection of $T$. gondii in humans and animals. These chimeric antigens are proteins with immunoreactive epitopes from selected antigens of $T$. gondii. These immunoreactive epitopes have highly exposed protein surfaces which are readily recognized by the receptors of T cells and B cells (Saha \& Raghava, 2006). Researchers developed the predictive chimeric epitope based on computer modeling of $T$. gondii. Modeling depends on the physio-chemical properties of amino acids and predicts the location and arrangement of peptide epitopes. Predictive software techniques were also used to evaluate the antigenic properties of chimeric epitopes from different $T$. gondii antigens (Dai et al., 2012; Wang et al., 2014b). Several research groups applied advanced techniques to recognize epitopes, such as phage display of cDNA libraries, epitope mapping, and monoclonal antibodies reactions (Cardona et al., 2009). Beghetto et al. (2006) used IgM Rec-ELISAs based on GST-EC2 and GST-EC3 chimeric antigens to diagnose toxoplasmosis in both acquired and congenital patients and reported $70 \%$ positive results with IgM Rec-ELISA and $35 \%$ positive results with commercially available assays (ELFA-IgM bioMérieux, France or ETI-TOXOK-M Diasorin, Italy). This provides strong evidence for the efficacy of this type of antigen. In another study, Holec-Gasior et al. (2012) found a higher sensitivity of IgG-ELISA for MIC1-MAG1 recombinant chimeric antigen $(90.8 \%)$ than individual recombinant antigens rMAG1 (60\%), rMIC1ex2 $(75.5 \%)$, or their mixture $(69.1 \%)$. It was also found that trivalent recombinant MIC1-MAG1-SAG1 chimeric antigen had a more satisfactory result than MIC1, MAG1, or bivalent recombinant MIC1-MAG1 chimeric antigen. These findings suggest that chimeric antigens formed with more protein units may be more effective (Holec-Gasior et al., 2012a). Ferra et al. (2015a) used five trivalent recombinant chimeric antigens (MIC1-MAG1-SAG1S, SAG1L-MIC1-MAG1, SAG2-GRA1ROP1S, SAG2-GRA1-ROP1L, and GRA1-GRA2-GRA6) in IgG-ELISA to detect $T$. gondii in horses, pigs, and sheep. Their team found a sensitivity and specificity ranging from $90 \%$ to $100 \%$ (Ferra et al., 2015a). Recently, a group of researchers developed tetravalent chimeric antigens from SAG2, GRA1, ROP1, and AMA1 antigen precursors (SAG2-GRA1-ROP1AMA1N, AMA1N-SAG2-GRA1-ROP1, AMA1C-SAG2-GRA1-ROP1, and AMA1-SAG2-GRA1-ROP1) which have $100 \%$ sensitivity and specificity in IgG-ELISAs (Tomasz et al., 2019). Moreover, combination of the peptide microarray analysis and predictive computer programing is an advanced and robust tool for the diagnosis of $T$. gondii. In this combined technology B cell epitopes, such as SAG1, SAG2, SAG3, GRA5, GRA6 and P35 are frequently used (Dai et al., 2012). Three recombinant epitopes (SAG1-EP2, SAG2-EP1, and SAG3-EP2, derived from SAG1, SAG2 and SAG3, respectively) were used for the development of a recombinant multiepitope fusion peptide
( $r M E P)$, which is more effective at distinguishing between recent and past $T$. gondii infection (Dai et al., 2012, 2013). In addition, two recombinant multiepitope based antigens, ROP $1_{L}$ and USM.TOXO1 were derived from SAG2, GRA1, ROP1 and SAG1, GRA2, GRA7, respectively. The recombinant antigens had $100 \%$ sensitivity and specificity in IgG-ELISA and Western blot (Ferra et al., 2015b; Hajissa et al., 2015). In an additional validation study with 157 human serum samples, USM.TOXO1 had a sensitivity of $85.43 \%$ and specificity of $81.25 \%$ (Hajissa et al., 2017). The chimeric epitopes and multiepitope peptides used for the diagnosis of $T$. gondii infection in humans and animals are listed in Table 4.

\section{Molecular detection and genotyping techniques}

\section{Polymerase chain reaction (PCR)}

Polymerase chain reaction (PCR) is widely used for the identification of $T$. gondii infection since it was first used by Burg et al. (1989) to target the B1 gene (Marques et al., 2020; Ngui et al., 2020; Tehrani et al., 2020). It is also accounted for higher target gene fragments amplifications, sensitivity and specificity. However, sensitivity and specificity are also affected by other factors such as DNA extraction technique, the primers, and the parameters of the amplification reaction (Edvinsson et al., 2004). There are a variety of PCR techniques, including conventional, nested, and real-time PCRs (Fallahi et al., 2014a; Marques et al., 2020). In PCR analysis of $T$. gondii infections, various body fluids, placenta, brain, blood, faeces, and urine can be used as samples (Schares et al., 2008).

In conventional PCR, single-copy targeting genes, such as SAG1, SAG2, SAG3, GRA1, SAG4, and GRA4, are used to detect $T$. gondii in humans and animals (Switaj et al., 2005). However, the sensitivity and specificity is low, especially in blood samples (Liu et al., 2015). Therefore, PCR targeting multicopy genes, including B1 gene, 529 bp repeat element, and $18 \mathrm{~S}$ rDNA gene, have been developed to improve sensitivity and specificity (Chabbert et al., 2004; Liu et al., 2015). Athough, the B1 gene with 35 repeats is considered the gold standard target for PCR detection of $T$. gondii in humans and animals (Chabbert et al., 2004), studies has shown that PCR with the 529 bp repeat element is ten to hundred times more sensitive than that of B1 gene (Reischl et al., 2003). Furthermore, similar sensitivity to the $B 1$ gene has been documented for the internal transcribed spacer (ITS-1) and 18S rDNA multi-copy genes (Calderaro et al., 2006). Functionally, conventional PCR is effective for the diagnosis of toxoplasmosis in congenitally infected prenatal babies (sensitivity 64.0 to $97.4 \%$ ) as well as in immuno-deficient patients (sensitivity 13.0 to $87.5 \%$ ) (Switaj et al., 2005).

With the advancement of technology, a hybrid diagnostic technique has been developed by combining conventional PCR and Southern blotting with a specific probe. This technique requires an extra 12-24 hours to complete following conventional PCR (Liu et al., 2015). Another PCR technique is the PCR-ELISA, a sero-molecular diagnostic assay developed by Emrich and Karl (2020). This assay uses hybridization with an immobilized capture probe to detect sequences within the PCR product. The PCR-ELISA assay has been adapted to use polystyrene beads which decreases the time requirement. The sensitivity of this method is similar to Southern blotting (Martinez et al., 2003). In addition, a magnetic capture method combined with conventional PCR has been developed, which can detect and genotype $T$. gondii in meat samples (Opsteegh et al., 2010). 


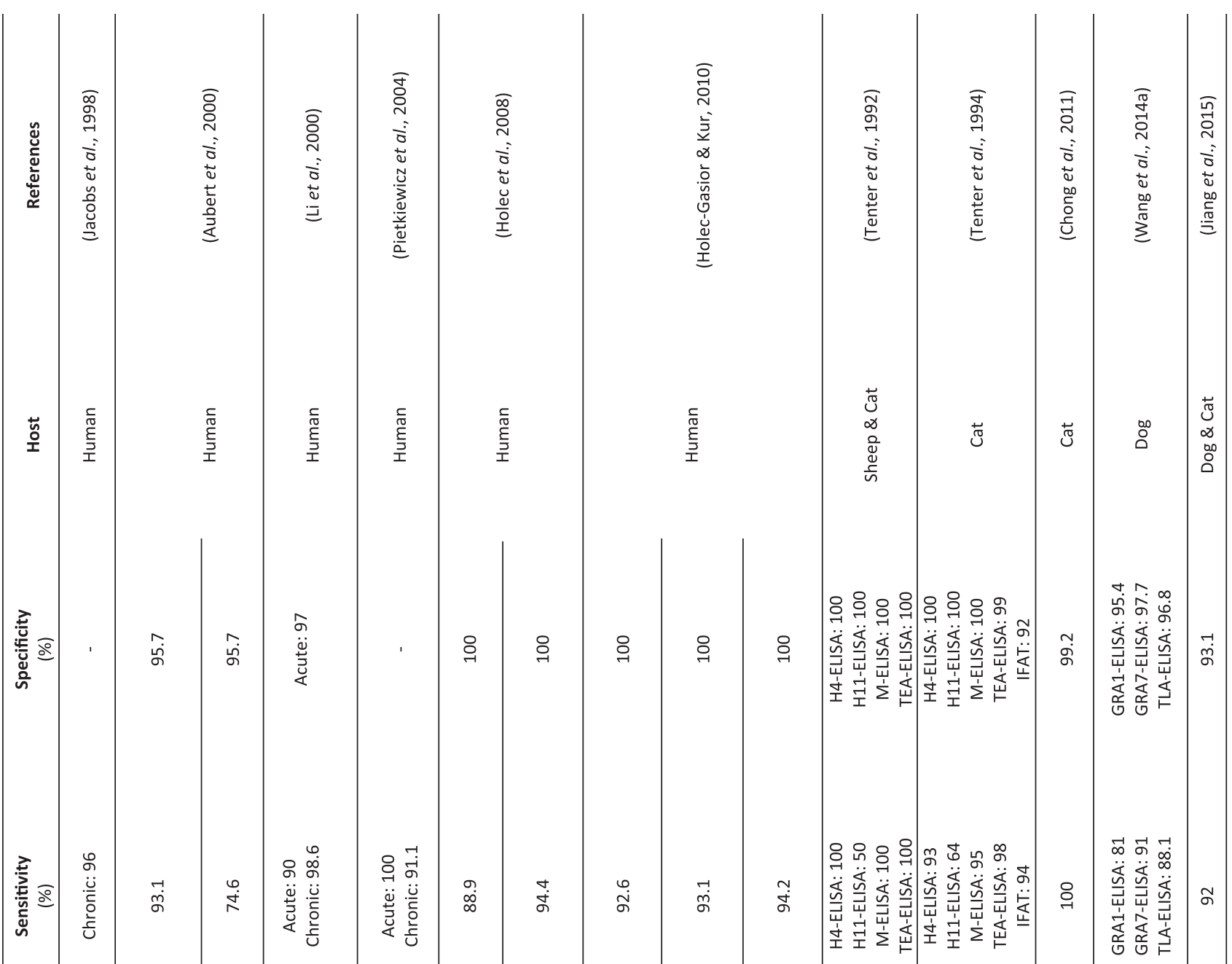
AataAa Aa Aa a A A A A A A A A A A

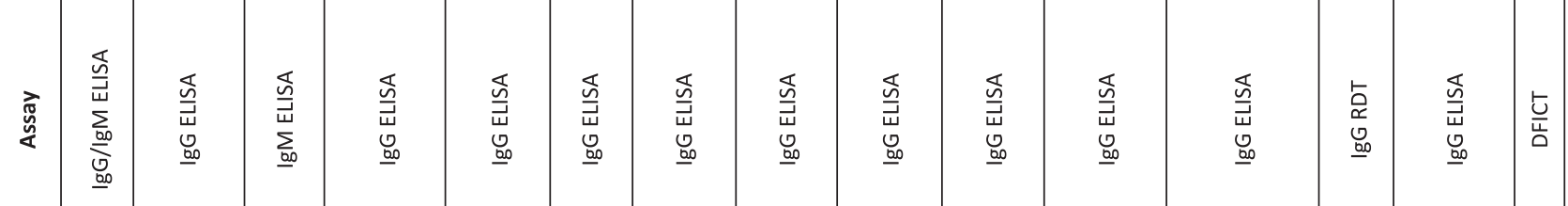

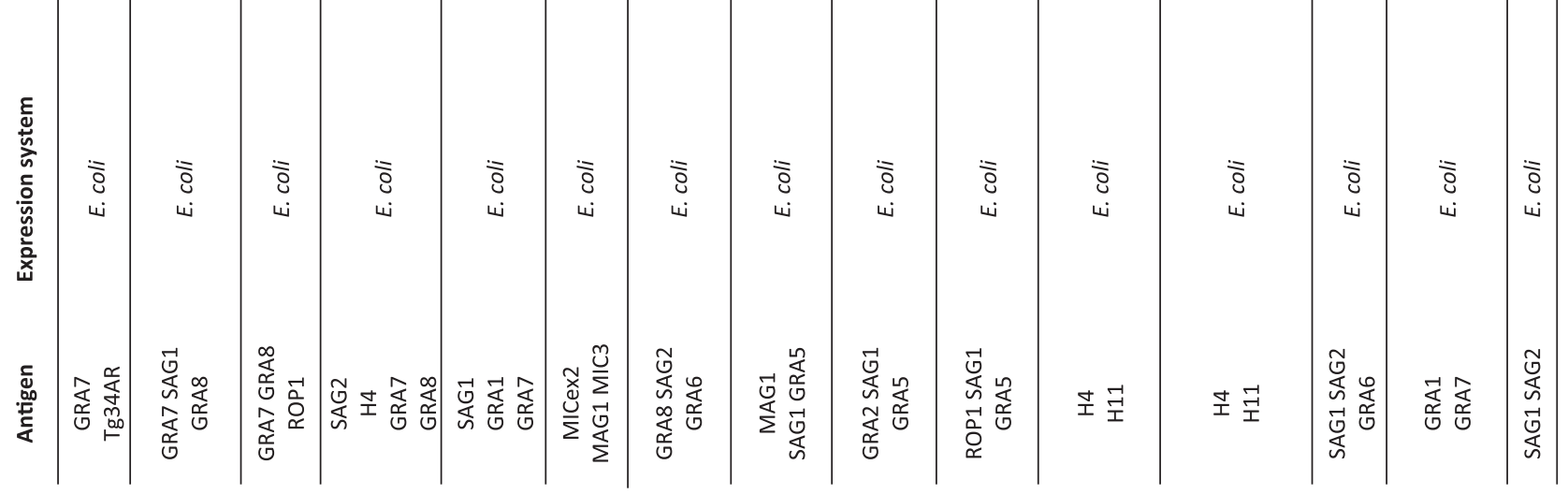


Uddin et al. (2021), Tropical Biomedicine 38(4): 511-539

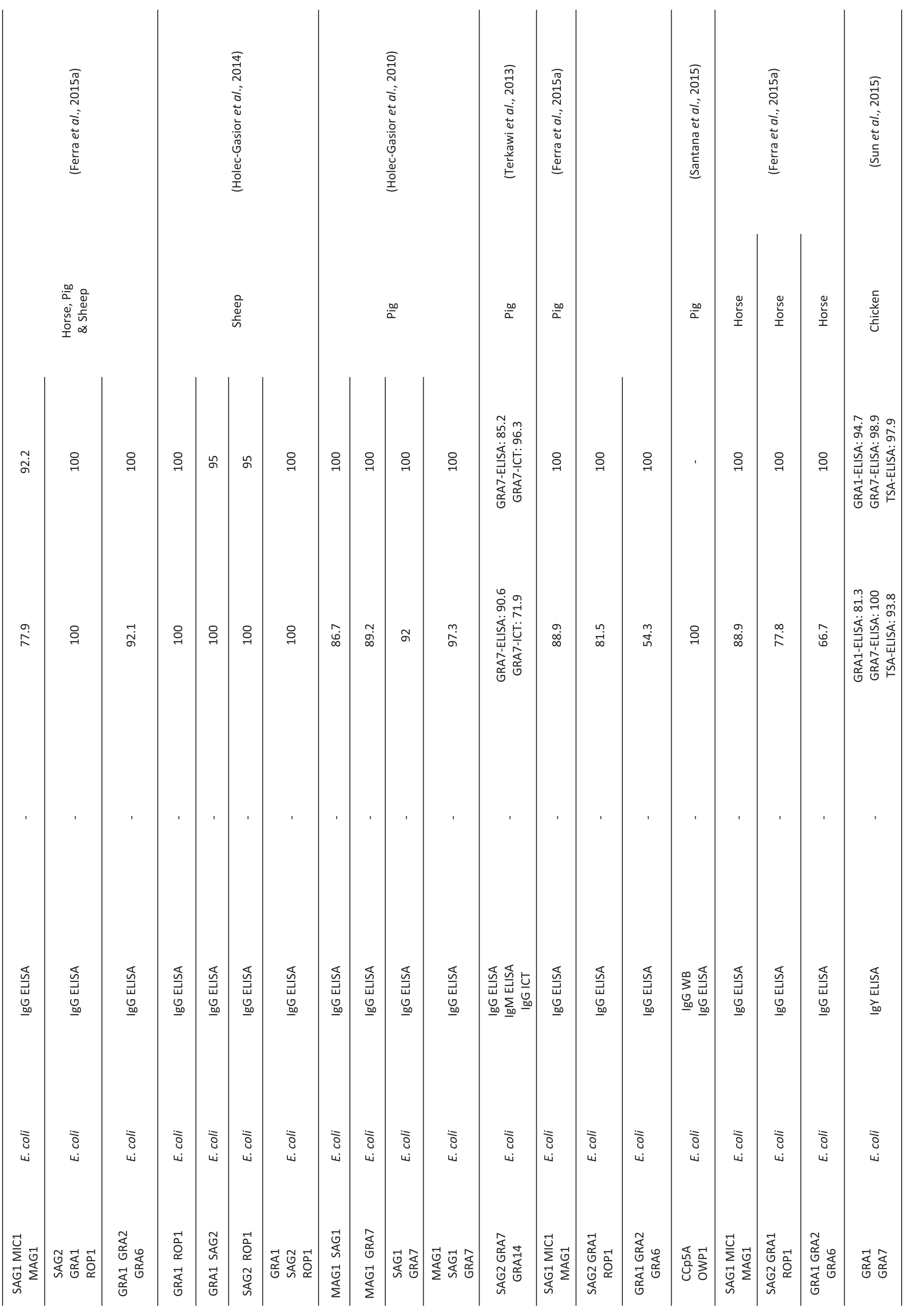




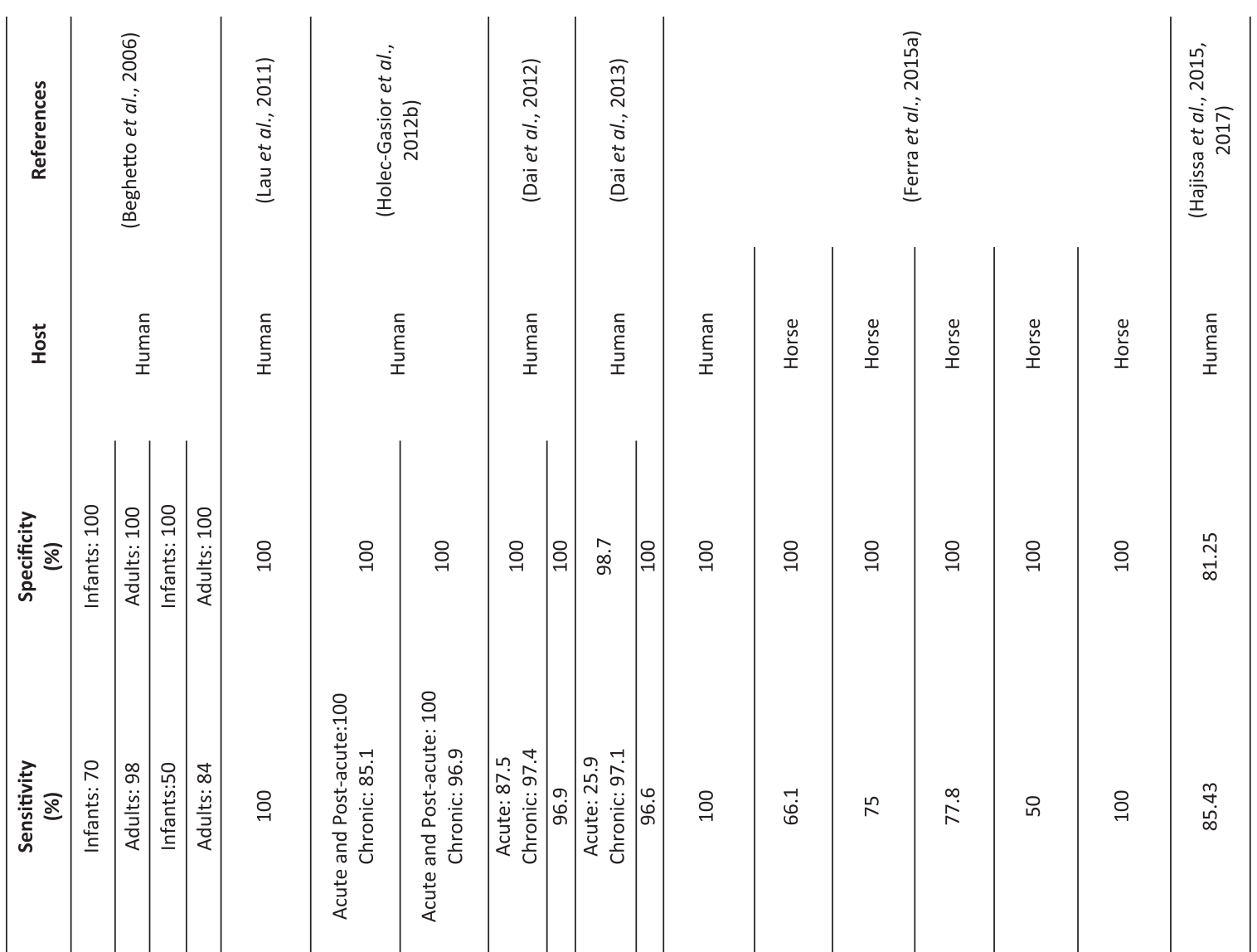




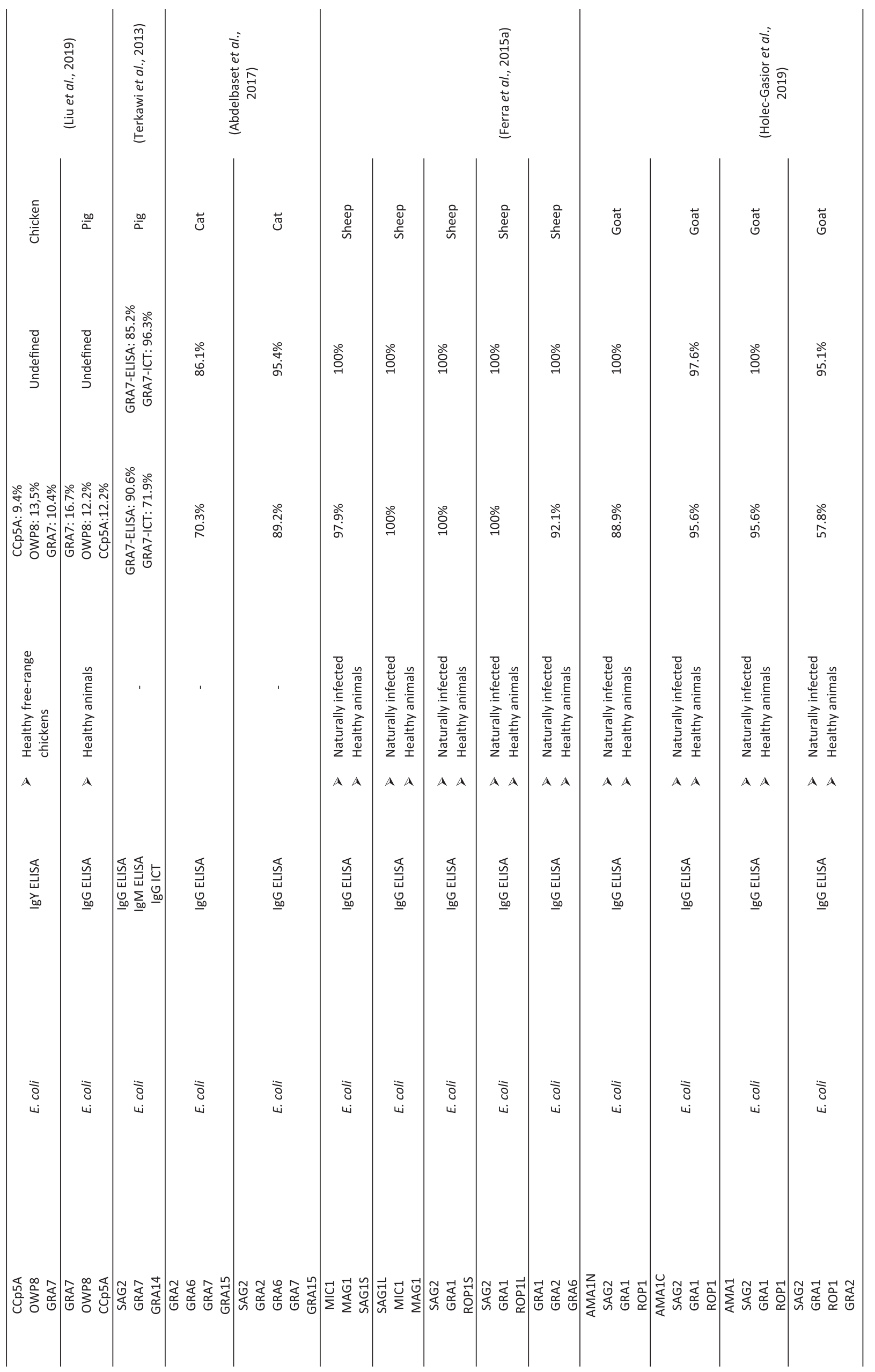


Nested PCR is another PCR technique used to identify $T$. gondii. In this technique, two sets of primers are allowed to run consecutively and the products of the first reaction becme templates for the second reaction. This technique was developed to increase sensitivity and specificity (Jones et al., 2000; Fallahi et al., 2014a) (Table 5). The B1 gene is primarily used for the identification of $T$. gondii with this type of PCR (Botein et al., 2019; Nakashima et al., 2020; Ngui et al., 2020). However, the Me49, GRA6, and Rep529 genes have also been used as targets (Mousavi et al., 2016; Bahadori et al., 2019; Shahbazi et al., 2019). It is noteworthy that both the B1 and REP 529 genes of $T$. gondii show more sensitivity and specificity in nested PCR than conventional PCR (Jones et al., 2000; Fallahi et al., 2014b).

Unlike conventional and nested PCRs, real-time PCR is capable of identifying a very low amount of target genes. The amplified product can then be measured in standard concentration during every cycle using probes (Liu et al., 2015) (Table 6). In addition, the elimination of contaminants through a rapid closed tube system has allowed for standardization of real-time PCR. Aside from detecting $T$. gondii infection, real-time PCR can also measure the magnitude of infection. Thus, this technique could be used evaluate disease progression and the effectiveness of treatment. Teixeira et al. (2013) showed that real-time PCR targeting the B1 gene is more effective at diagnosing congenital toxoplasmosis than conventional or nested PCRs. Me49, Rep529, ITS-1, and P30 genes are also used as targets in real-time PCR for the diagnosis of toxoplasmosis (Marques et al., 2020). A combination of magnetic capture and realtime PCR can identify predilection sites of $T$. gondii and its intensity in domestic animals.

\section{Loop mediated isothermal amplification (LAMP)}

Loop mediated isothermal amplification is a modified nucleic acid amplification assay under isothermal conditions $\left(60-65^{\circ} \mathrm{C}\right)$. It uses $4-6$ specific primers, which can identify 6-8 distinct regions within the target DNA with high sensitivity, specificity, and speed (Alhassan et al., 2007; Abbasi et al., 2010; Gallas-Lindemann et al., 2013). LAMP is easy, reliable, inexpensive, and does not require a highly equipped reference laboratory (Mori \& Notomi, 2009). These advantages have inspired many researchers to use this test in a variety of animal samples (Hu et al., 2012; Dai et al., 2013; Wang et al., 2013; Fallahi et al., 2015). This molecular technique is able to detect $T$. gondii in a variety of samples including blood (Mikita et al., 2013; Sun et al., 2017), water (GallasLindemann et al., 2013) and environmental air (Lass et al., 2017). LAMP's sensitivity is higher than conventional PCR and lower than real time PCR (Zhang et al., 2014). However, a recent study suggested that LAMP is more satisfactory than both conventional and real time PCR for the detection of $T$. gondii in congenital and immunocompromised patients (Rostami et al., 2018). Different target genes, incuding SAG1, SAG2, GRA1, B1, 18S rRNA, 529-bp REP and oocyst wall protein (OWP) can be identified by LAMP (Lau et al., 2010b; Hu et al., 2012; Qu et al., 2013). In LAMP assay, SAG1 and SAG2 target genes are most useful for the diagnosis of early and active toxoplasmosis (Wang et al., 2013). SAG1, SAG2 and B1 target genes are typically used to identify $T$. gondii in human blood samples (Lau et al., 2010b; Hu et al., 2012; Mikita et al., 2013). 18s rRNA and REP 529 target genes are used in a modified LAMP assay and reverse transcription LAMP (RT-LAMP) to detect T. gondii in mice and meat samples (Qu et al., 2013).

\section{Microsatellite analysis (MSA)}

Microsatellite analysis (MSA) is based on the identification of short tandem repeats (2-6 nucleotides) in DNA. Markers generated from repeated nucleotides are highly polymorphic because of length variations and they have multiple alleles, which make them reliable for genotypic investigations. Various MS marker sets (with 515 markers) have been used in research studies (Ajzenberg et al., 2010). A multiplex PCR technique for 15 MSs allowing multilocus analysis of isolates by a single PCR amplification has been developed for the high resolution genotyping of $T$. gondii strains (Ajzenberg et al., 2010). The mutation rate for MSs is $10^{-22}-10^{-25}$ per locus per replication, which is faster than single nucleotide polymorphisms (SNPs) (Bond, 2000). However, a high rate of mutation is a limits the use of these makers due to homoplasy. In $15 \mathrm{MS}$ multiplex PCR, homoplasy has been diminished by the selection of variable and numerous MS markers located on 11 different chromosomes. The eight MS markers ([TG/AC]n, or [TC/AG]n: TUB2, W35, TgM-A, B18, B17, M33, IV.1 and XI.1) showed lower mutability but were able to differentiate major clonal lineages from atypical strains. Seven MS markers ([TA/ AT]n: M48, M102, N60, N82, AA, N61 and N83) are standard for distinguishing closely related isolates or analyzing the intratype population structure. The Simpson's index of diversity, tested on 369 type II isolates, was found to be 0.999 , which almost reaches the maximum of 1.0 (Ajzenberg et al., 2010). The degree of polymorphism is enhanced by MS markers and the rapid mutation rate makes microsatellite analysis techniques important for molecular epidemiology, forrecent evolution, and for individual identification of $T$. gondii isolates (Vielmo et al., 2019).

\section{Multilocus sequence typing (MLST)}

The Multilocus sequence typing technique (MLST) efficiently identifies DNA sequence polymorphisms, such as single nucleotide polymorphisms (SNPS). SNPs occur due to the insertion and deletion of nucleotides at different loci in the genome. Thus, the MLST technique has a higher resolution than techniques using single locus typing. However, MLST does require a large amount of genomic DNA. The MLST of $T$. gondii is usually based on the amplification and sequencing of Apico, B1, BTUB, c22-8, c29-2, L358, PK1, SAG1, SAG2, SAG3, and SAG4 gene loci (Su et al., 2006; Dubey et al., 2008). The requirement for a large quantity of genomic DNA limits the use of MLST for identification of $T$. gondii in clinical samples (Liu et al., 2015).

\section{PCR-restriction fragment length polymorphisms (PCR-RFLPS)}

The PCR-restriction fragment length polymorphisms (PCRRFLPs) is based on the ability of restriction endonucleases to identify single nucleotide polymorphisms (SNPs). After the PCR products are treated with restriction enzymes, they are visualized via electrophoresis in agarose or polyacrylamide gels. Each SNPs has a variable length band pattern (Howe \& Sibley, 1995). Type I, II, and III linages were identified from $106 \mathrm{~T}$. gondii strains isolated from both humans and animals. Isolation was done by PCR-RFLP using six markers (Howe \& Sibley, 1995). Conventional PCR-RFLPs depends on single-copy polymorphic DNA sequences, and always requires a large amount of DNA. This is a major limitation of conventional PCR-RFLPs when attempting to genotype $T$. gondii isolated from biological samples (Liu et al., 2015). In order to overcome the shortcomings of conventional PCR-RFLPs, a new approach was developed: 


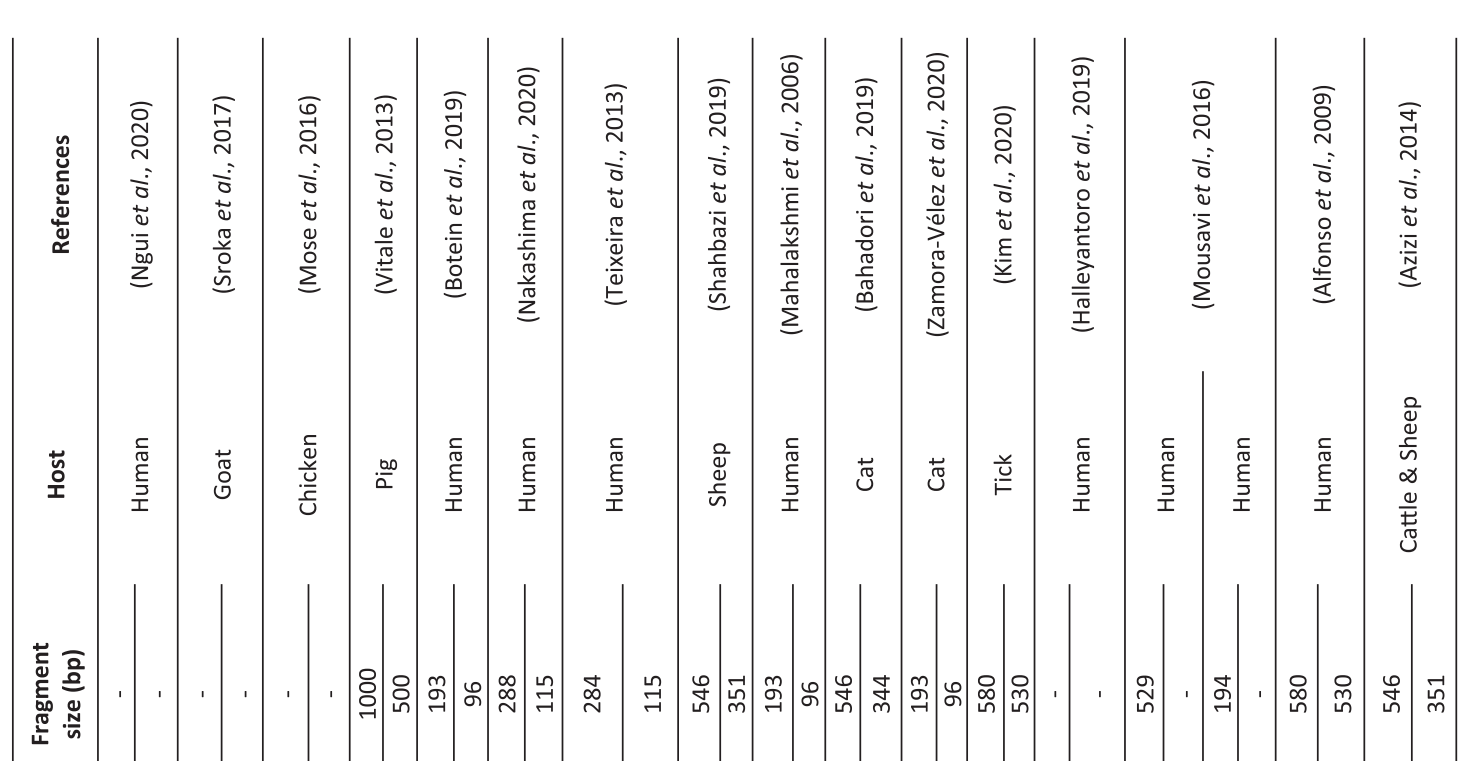

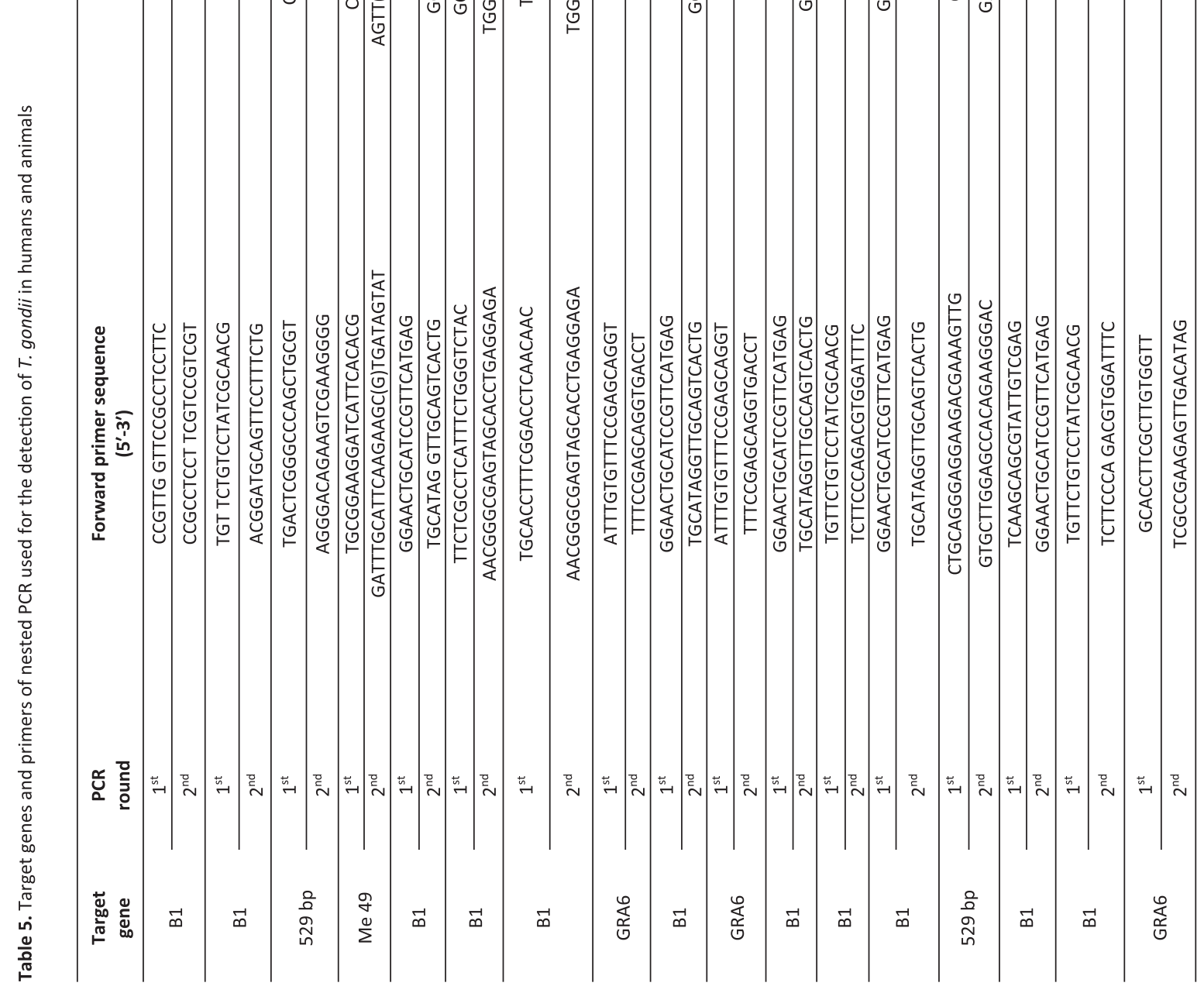




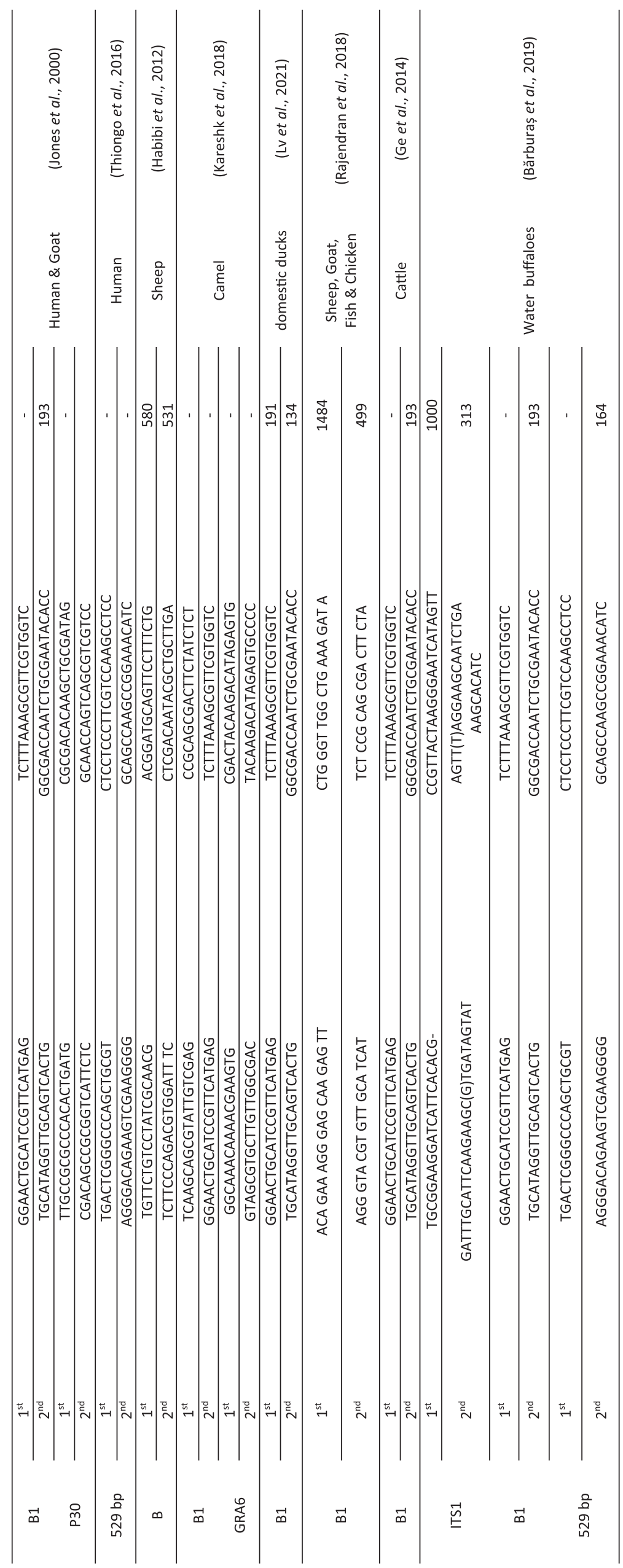




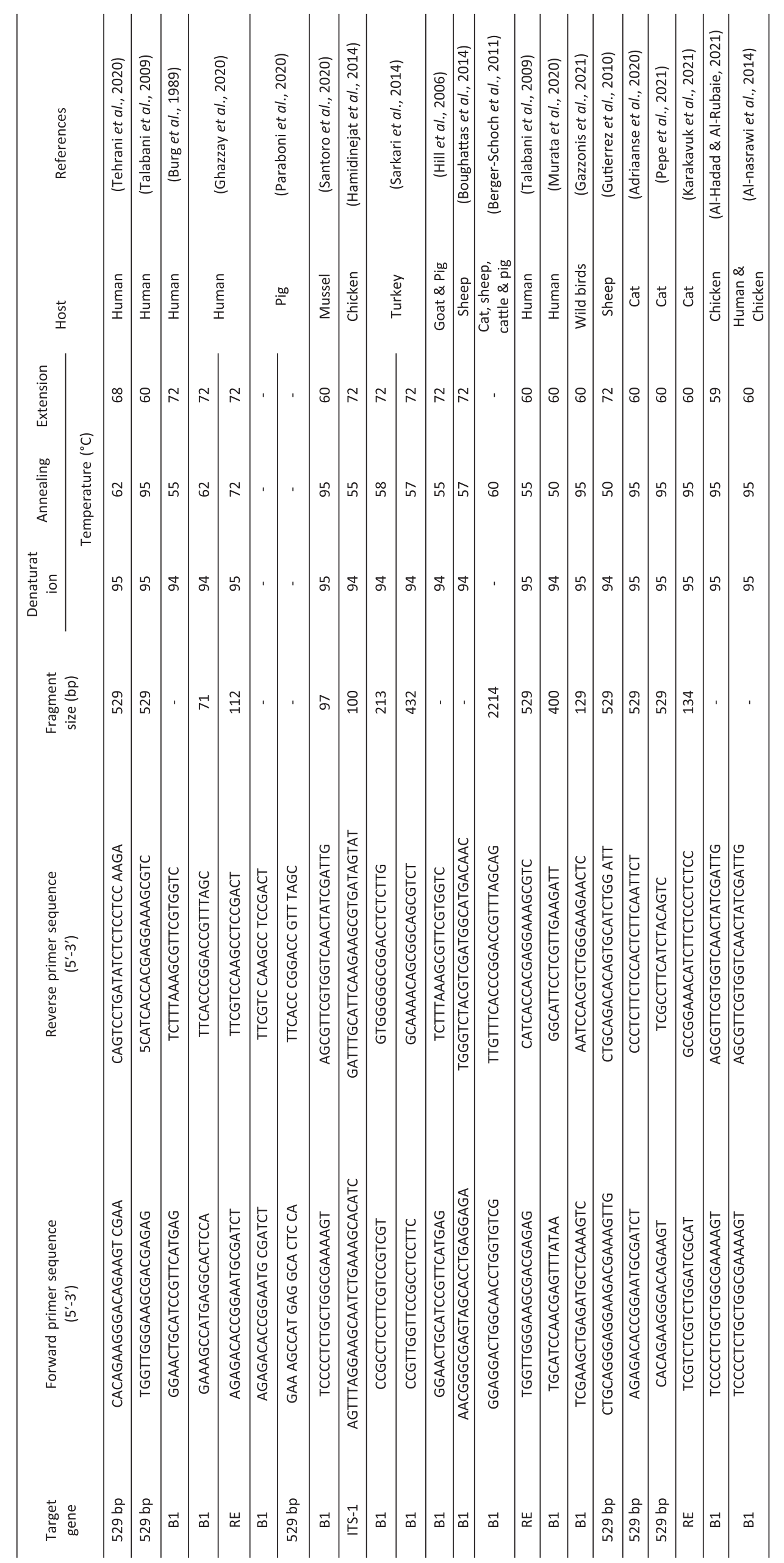


multiplex multilocus nested PCR-RFLPs (Mn-PCR-RFLPs). This technique uses 10 genetic markers (SAG1, SAG2, SAG3, BTUB, GRA6, c22-8, c29-2, L358, PK1 and Apico) and has been shown to have satisfactory sensitivity (Dubey et al., 2007). Mn-PCRRFLP has been widely used to type clinically isolated positive samples. It has also been used to determine the genetic diversity and population structure of $T$. gondii (Zhou et al., 2013). One concern with this test is that incorrect findings may be produced if contamination occurs in the early cycles of PCR. In order to prevent this error, a negative control must be used in each experiment (Liu et al., 2015).

\section{Random amplified polymorphic DNA-PCR (RAPD-PCR)}

The Random amplified polymorphic DNA-PCR (RAPD-PCR) is used to identify DNA polymorphisms based on the amplification of genomic DNA with single short arbitrary primers under low stringency conditions (Liu et al., 2015). RAPD-PCR is excellent at identifying genetic differentiation among closely related species and has been used to classify the genotype of T. gondii strains (Ferreira et al., 2004). T. gondii can be categorized into virulent and avirulent strains based on murine virulence by RAPD-PCR. Certain primers are useful for detecting virulence markers. Although it is a fast, easy, and effective technique, RAPD-PCR band profiles can be difficult to replicate, even within individual laboratories, if the staff, facilities or conditions are altered. For this assay, only a small amount of DNA is needed, but it must be very pure (Arif et al., 2010). Thus, for clinical samples, RAPD-PCR is not useful (Liu et al., 2015).

\section{High-resolution melting (HRM)}

The high-resolution melting (HRM) is a homogeneous, closetube and post-PCR tool for the study of genetic variants. It characterizes polymorphisms based on their melting temperature, which is associated with the polymorphism sequence, length, and GC content (Jex et al., 2008). HRM analysis can accurately distinguish $T$. gondii strains into three distinct groups based on a single SNP of the multicopy B1 gene (Costa et al., 2011). HRM is more descriptive than the study of microsatellites, thus it provides an additional test for multilocus microsatellite analysis (Costa et al., 2011, 2013). This method was developed to directly genotype $T$. gondii from biological samples. Its genotyping ability is better with multi-copy genes rather than single-copy gene, thereby avoiding cell culture or bioassay (Costa et al., 2013). HRM may provide an easy solution for genotyping, mutation scanning, and sequence matching (Liu et al., 2015).

\section{Metagenomics analysis (MGA)}

Metagenomics analysis (MGA) is based on the identification of causal agents from unknown independent environmental samples (Greninger, 2018). No prerequisite information about specific infectious agents is required for metagenomics. Metagenomics can detect every infectious and non-infectious pathogen in a single sample using bioinformatics and computational strategy (Hu et al., 2018). A group of researchers applied metagenomics to identify unknown causal agents in the brain lesions of a human immunodeficiency virus (HIV) infected patient. They identified $T$. gondii by analyzing a genomic sequence found in the cerebrospinal fluid (CSF) of the patient (Hu et al., 2018). Thus, metagenomics analysis may be an important diagnostic tool for the identification of toxoplasmic encephalitis. However, the method needs more assessment as a diagnostic tool for toxoplasmosis.

\section{Whole-genome sequencing (WGS)}

Whole-genome sequencing (WGS) involves the identification of the complete DNA sequence of an organism's genome in a single shot. At the present time, sixteen haplogroups of $T$. gondii containing over one hundred whole-genome sequences are stored in the Sequence Read Archive (SRA) (https://www.ncbi.nlm.nih.gov/sra). A total of 14 chromosomes were identified from the whole-genome shotgun sequences (www.toxodb.org) (Kissinger et al., 2003) and composite genome map (types III strains) of $T$. gondii (Khan et al., 2005; Sibley, 2009). These sequences were obtained using next-generation sequencing (NGS) platforms, such as Illumina HiSeq or MiSeq (Lorenzi et al., 2016). NGS enhances variations in structure and copy number, to identify recombinant strains of $T$. gondii at the whole-genome level. Currently, 62 strains with 138 unique genotypes from 15 different haplogroups of $T$. gondii have been submitted to WGS and ref-mapped against ME49 (Lorenzi et al., 2016). A total of 802,764 SNPs have been identified in the T. gondii genome using whole genome comparison analysis. It is providing new insignt into the genomics of $T$. gondii. This helps researchers identify the ancestral origin, evolution, hybridization, distribution, and transmission of different $T$. gondii strains worldwide. However, this method has several challenges, such as parasite isolation, parasite purificant in cell culture, DNA extraction for sequencing, expense, a technically laborious and challenging procedure (Lorenzi et al., 2016).

\section{CONCLUSIONS}

In the current era, accurate diagnosis of $T$. gondii infection is imperative in humans and animals due to its public health importance. This review has attempted to review all advanced and contemporary diagnostic techniques for the detection and genetic characterization of $T$. gondii. Over the previous three decades, direct microscopic and bioassays methods were commonly applied to identify $T$. gondii. However, some unavoidable limitations and difficulties of the methods drove researchers to develop effective serological and molecular techniques for the efficient identification and interpretation of $T$. gondii infection in humans and animals. In this process, a number of molecular and serological methods were developed. Currently, molecular and serological diagnosis plays an important role in the identification of $T$. gondii infection. The advantages, disadvantages, sensitivity, specificity and limitations of different serological tests are having been addressed in a wide variety of studies and methods are revised on a continuous basis to enhance their efficacy. This continuous research and revision led to the identification of recombinant proteins (single and combination) and chimeric antigens that can be used for the serological detection of $T$. gondii infections. These recombinant proteins and chimeric antifens can overcome some of the limitations of serological tests as well as improve their sensitivity and specificity. The key success of recombinant proteins and chimeric antigens is the identification of different phases of $T$. gondii infections. Similarly, numerous molecular techniques, including PCR, LAMP, microsatellite analysis, MLST, PCR-RFLP, RAPD-PCR, HRM, metagenomics analysis and WGS, have been applied for the detection and genetic characterization of $T$. gondii. After extracting findings from a wide variety of studies, we concluded that recombinant proteins in single and/or 
combination forms and chimeric epitope are highly recommended for the diagnosis of $T$. gondii infections. Diagnostic methods based on recombinant proteins based have satisfactory sensitivity and specificity and are standardized and cost effective.

In the process of toxoplasmosis diagnostic advancement, researchers should focus on integrating genomic technologies, including genomics, transcriptomics, proteomics, and metabolomics. This research would help obtain a more comprehensive understanding of the pathogenesis and immune mechanisms of the parasite. It would also aid in the development of vaccines. Additionally, advancements in bioinformatics technologies would help with further genetic characterization of $T$. gondii and potentially provide new options for the diagnosis of toxoplasmosis.

\section{ACKNOWLEDGEMENTS}

We gratefully acknowledge Dr. Sanna Gough, Small Animal Emergency and Critical Care Resident, University of Georgia, College of Veterinary Medicine, Athens, Georgia, USA, for her outstanding contributions to critical English revision as a native speaker.

\section{Conflict of Interest}

The authors have declared that no competing interests exist.

\section{REFERENCE}

Abbas, I.E., Villena, I. \& Dubey, J.P. (2020). A review on toxoplasmosis in humans and animals from Egypt. Parasitology 147: 135-159. https://doi.org/10.1017/ S0031182019001367

Abbasi, I., King, C.H., Muchiri, E.M. \& Hamburger, J. (2010). Detection of Schistosoma mansoni and Schistosoma haematobium DNA by loop mediated isothermal amplification: identification of infected snails from early prepatency. The American Journal of Tropical Medicine and Hygiene 83: 427-432. https://doi.org/10.4269/ajtmh.2010.090764

Abdelbaset, A.E., Alhasan, H., Salman, D., Karram, M.H., Ellah Rushdi, M.A., Xuenan, X. \& Igarashi, M. (2017). Evaluation of recombinant antigens in combination and single formula for diagnosis of feline toxoplasmosis. Experimental Parasitology 172: 1-4. https://doi.org/10.1016/ j.exppara.2016.11.003

Adriaanse, K., Firestone, S.M., Lynch, M., Rendall, A.R., Sutherland, D.R., Hufschmid, J. \& Traub, R. (2020). Comparison of the modified agglutination test and real time PCR for detection of Toxoplasma gondii exposure in feral cats from Phillip Island, Australia, and risk factors associated with infection. International Journal for Parasitology: Parasites and Wildlife 12: 126-133. https://doi.org/ 10.1016/j.jppaw.2020.05.006

Ajzenberg, D., Collinet, F., Mercier, A., Vignoles, P. \& Dardé, M.L. (2010). Genotyping of Toxoplasma gondii isolates with 15 microsatellite markers in a single multiplex PCR assay. Journal of Clinical Microbiology 48: 4641-4645. https://doi.org/ 10.1128/JCM.01152-10

Al-Adhami, B.H., Simard, M., Hernández-Ortiz, A., Boireau, C. \& Gajadhar, A.A. (2016). Development and evaluation of a modified agglutination test for diagnosis of toxoplasma infection using tachyzoites cultivated in cell culture. Food and Waterborne Parasitology 2: 15-21. https://doi.org/ 10.1016/j.fawpar.2015.12.001
Alfonso, Y., Fraga, J., Jiménez, N., Fonseca, C., Dorta-Contreras, A.J., Cox, R., Capó, V., Bandera, F., Pomier, O. \& Ginorio, D. (2009). Detection of Toxoplasma gondii in cerebrospinal fluid from AIDS patients by nested PCR and rapid identification of type I allele at B1 gene by RFLP analysis. Experimental Parasitology 122: 203-207. https://doi.org/ 10.1016/j.exppara.2009.03.009

Al-Hadad, E.J.K. \& Al-Rubaie, H.M.A. (2021). Molecular detection of Toxoplasma Gondii in local breed domestic chickens (Gullas Gullas Domesticus) in Baghdad city, Iraq. Plant Archives 21: 1281-1286. https://doi.org/10.51470/ PLANTARCHIVES.2021.v21.S1.202

Alhassan, A., Thekisoe, O.M.M., Yokoyama, N., Inoue, N., Motloang, M.Y., Mbati, P.A., Yin, H., Katayama, Y., Anzai, T. \& Sugimoto, C. (2007). Development of loop mediated isothermal amplification (LAMP) method for diagnosis of equine piroplasmosis. Veterinary Parasitology 143: 155160. https://doi.org/10.1016/j.vetpar.2006.08.014

Al-Malki, E. (2021). Toxoplasmosis: stages of the protozoan life cycle and risk assessment in humans and animals for an enhanced awareness and an improved socio economic status. Saudi Journal of Biological Sciences 28: 962969. https://doi.org/10.1016/j.sjbs.2020.11.007

Al-nasrawi, H.A.A., Naser, H.H. \& Kleaf, S.F. (2014). Molecular detection of Toxoplasma gondii in human and chicken by real-time PCR technique. International Journal of Advanced Research 2: 1023-1027.

Andreoletti, O., Budka, H., Buncic, S., Colin, P., Collins, J.D., Koeijer, A., Griffin, J., Havelaar, A., Hope, J., Klein, G. et al. (2007). Surveillance and monitoring of toxoplasma in humans, food and animals. Scientific opinion of the panel on biological hazards. The European Food Safety Authority Journal 583: 1-64.

Arif, I.A., Bakir, M.A., Khan, H.A., Al-Farhan, A.H., Al-Homaidan, A.A., Bahkali, A.H., Al-Sadoon, M. \& Shobrak, M. (2010). A brief review of molecular techniques to assess plant diversity. International Journal of Molecular Sciences 11: 20792096. https://doi.org/10.3390/ijms11052079

Aubert, D., Maine, G.T., Villena, I., Hunt, J.C., Howard, L., Sheu, M., Brojanac, S., Chovan, L.E., Nowlan, S.F. \& Pinon, J.M. (2000). Recombinant antigens to detect Toxoplasma gondiispecific immunoglobulin $G$ and immunoglobulin $M$ in human sera by enzyme immunoassay. Journal of Clinical Microbiology 38: 1144-1150. https://doi.org/10.1128/JCM. 38.3.1144-1150.2000

Azizi, H., Shiran, B., Boroujeni, A.B. \& Jafari, M. (2014). Molecular survey of Toxoplasma gondii in sheep, cattle and meat products in Chaharmahal va Bakhtiari province, Southwest of Iran. Iranian Journal of Parasitology 9: 429-434.

Bachan, M., Deb, A.R., Maharana, B.R., Sudhakar, N.R., Sudan, V., Saravanan, B.C. \& Tewari, A.K. (2018). High seroprevalence of Toxoplasma gondii in goats in Jharkhand state of India. Veterinary Parasitology: Regional Studies and Reports 12: 61-68. https://doi.org/10.1016/j.vprsr.2018.02.004

Bahadori, E.S., Sadraei, J. \& Dalimi, A. (2019). New prevalence surveillance of Toxoplasma gondii among rodents and stray cats by ELISA avidity and nested PCR methods, Northeast of Iran. Journal of Parasitic Diseases 43: 360-367. https:// doi.org/10.1007/s12639-019-01099-2

Barburaş, D., Gyçrke, A., Blaga, R., Barburaș, R., Kalmár, Z., Vişan, S., Mircean, V., Blaizot, A. \& Cozma, V. (2019). Toxoplasma gondii in water buffaloes (Bubalus bubalis) from Romania: what is the importance for public health? Parasitology Research 118: 2695-2703. https://doi.org/10.1007/ s00436-019-06396-6 
Begeman, I.J., Lykins, J., Zhou, Y., Lai, B.S., Levigne, P., El-Bissati, K., Boyer, K., Withers, S., Clouser, F. \& Noble, A.G. (2017). Point-of-care testing for Toxoplasma gondii IgG/IgM using Toxoplasma ICT IgG-IgM test with sera from the United States and implications for developing countries. PLOS Neglected Tropical Diseases 11: e0005670. https://doi.org/ 10.1371/journal.pntd.0005670

Beghetto, E., Buffolano, W., Spadoni, A., Pezzo, M., Cristina, M., Minenkova, O., Petersen, E., Felici, F. \& Gargano, N. (2003). Use of an immunoglobulin $G$ avidity assay based on recombinant antigens for diagnosis of primary Toxoplasma gondii infection during pregnancy. Journal of Clinical Microbiology 41: 5414-5418. https://doi.org/10.1128/ JCM.41.12.5414-5418.2003

Beghetto, E., Spadoni, A., Bruno, L., Buffolano, W. \& Gargano, N. (2006). Chimeric antigens of Toxoplasma gondii: toward standardization of toxoplasmosis serodiagnosis using recombinant products. Journal of Clinical Microbiology 44: 2133-2140. https://doi.org/10.1128/JCM.00237-06

Béla, S.R., Silva, D.A.O., Cunha-Júnior, J.P., Pirovani, C.P., ChavesBorges, F.A., Carvalho, F.R., Oliveira, T.C. \& Mineo, J.R. (2008). Use of SAG2A recombinant Toxoplasma gondii surface antigen as a diagnostic marker for human acute toxoplasmosis: analysis of titers and avidity of IgG and IgG1 antibodies. Diagnostic Microbiology and Infectious Disease 62: 245-254. https://doi.org/10.1016/j.diagmicrobio. 2008.05.017

Bel-Ochi, N.C., Bouratbine, A. \& Mousli, M. (2013). Enzymelinked immunosorbent assay using recombinant SAG1 antigen to detect Toxoplasma gondii-specific immunoglobulin $\mathrm{G}$ antibodies in human sera and saliva. Clinical and Vaccine Immunology 20: 468-473. https://doi.org/10.1128/ CVI.00512-12

Berger-Schoch, A.E., Herrmann, D.C., Schares, G., Müller, N., Bernet, D., Gottstein, B. \& Frey, C.F. (2011). Prevalence and genotypes of Toxoplasma gondii in feline faeces (oocysts) and meat from sheep, cattle and pigs in Switzerland. Veterinary Parasitology 177: 290-297. https://doi.org/10.1016/ j.vetpar.2010.11.046

Bergersen, K.V., Barnes, A., Worth, D., David, C. \& Wilson, E.H. (2021). Targeted transcriptomic analysis of C57BL/6 and BALB/c mice during progressive chronic Toxoplasma gondii infection reveals changes in host and parasite gene expression relating to neuropathology and resolution. Frontiers in Cellular and Infection Microbiology 11: 1-19. https://doi.org/10.3389/fcimb.2021.645778

Bond, J. (2000). Microsatellites: Evolution and Applications. Edited D. B. Goldstein and C. Schlötterer, Oxford University Press, 1999. Genetical Research 75:123-125. https://doi.org/ 10.1017/S0016672300239141

Bonyadi, M.R. \& Bastani, P. (2013). Modification and evaluation of avidity IgG testing for differentiating of Toxoplasma gondii infection in early stage of pregnancy. Cell Journal 15: 238.

Botein, E.F., Darwish, A., El-Tantawy, N.L., EL-Baz, R., Eid, M.I. \& Shaltot, A.M. (2019). Serological and molecular screening of umbilical cord blood for Toxoplasma gondii infection. Transplant Infectious Disease 21: 1-8. https://doi.org/10.1111/ tid.13117

Boughattas, S., Ayari, K., Sa, T., Aoun, K. \& Bouratbine, A. (2014). Survey of the parasite Toxoplasma gondii in human consumed ovine meat in Tunis City. PLOS ONE 9: e85044. https://doi.org/10.1371/journal.pone.0085044

Boyden, S.V. (1951). The adsorption of proteins on erythrocytes treated with tannic acid and subsequent hemagglutination by antiprotein sera. The Journal of Experimental Medicine 93: 107. https://doi.org/10.1084/jem.93.2.107
Burg, J.L., Grover, C.M., Pouletty, P. \& Boothroyd, J.C. (1989). Direct and sensitive detection of a pathogenic protozoan, Toxoplasma gondii, by polymerase chain reaction. Journal of Clinical Microbiology 27: 1787-1792. https://doi.org/ 10.1128/jcm.27.8.1787-1792.1989

Burg, J.L., Perelman, D., Kasper, L.H., Ware, P.L. \& Boothroyd, J.C. (1988). Molecular analysis of the gene encoding the major surface antigen of Toxoplasma gondii. The Journal of Immunology 141: 3584-3591.

Cai, Y., Wang, Z., Li, J., Li, N., Wei, F. \& Liu, Q. (2015). Evaluation of an indirect ELISA using recombinant granule antigen GRA7 for serodiagnosis of Toxoplasma gondii infection in cats. The Journal of Parasitology 101: 37-40. https://doi.org/ 10.1645/14-575.1

Calderaro, A., Piccolo, G., Gorrini, C., Peruzzi, S., Zerbini, L., Bommezzadri, S., Dettori, G. \& Chezzi, C. (2006). Comparison between two real time PCR assays and a nested PCR for the detection of Toxoplasma gondii. Acta Bio-Medica: Atenei Parmensis 77: 75.

Calero-Bernal, R. \& Gennari, S.M. (2019). Clinical toxoplasmosis in dogs and cats: an update. Frontiers in Veterinary Science 6: 54. https://doi.org/10.3389/fvets. 2019.00054

Camargo, M.E. (1964). Improved technique of indirect immunofluorescence for serological diagnosis of toxoplasmosis. Revista Do Instituto de Medicina Tropical de São Paulo 6: 117-118.

Cardona, N., de-la-Torre, A., Siachoque, H., Patarroyo, M.A. \& Gomez-Marin, J.E. (2009). Toxoplasma gondii: P30 peptides recognition pattern in human toxoplasmosis. Experimental Parasitology 123: 199-202. https://doi.org/10.1016/ j.exppara.2009.06.017

Caruana, L.B. (1980). A study of variation in the indirect hemagglutination antibody test for toxoplasmosis. The American Journal of Medical Technology 46: 386-391.

Cazarotto, C.J., Balzan, A., Grosskopf, R.K., Boito, J.P., Portella, L.P., Vogel, F.F., Fávero, J.F., Cucco, D.C., Biazus, A.H. \& Machado, G. (2016). Horses seropositive for Toxoplasma gondii, Sarcocystis spp. and Neospora spp.: possible risk factors for infection in Brazil. Microbial Pathogenesis 99: 30-35. https://doi.org/10.1016/j.micpath.2016.07.016

Chabbert, E., Lachaud, L., Crobu, L. \& Bastien, P. (2004). Comparison of two widely used PCR primer systems for detection of toxoplasma in amniotic fluid, blood, and tissues. Journal of Clinical Microbiology 42: 1719-1722. https:/ /doi.org/10.1128/JCM.42.4.1719-1722.2004

Ching, X.T., Lau, Y.L., Fong, M.Y. \& Nissapatorn, V. (2013). Evaluation of Toxoplasma gondii-recombinant dense granular protein (GRA2) for serodiagnosis by western blot. Parasitology Research 112: 1229-1236. https://doi.org/ 10.1007/s00436-012-3255-5

Chong, C.K., Jeong, W., Kim, H.Y., An, D. J., Jeoung, H.Y., Ryu, J.E., Ko, A.R., Kim, Y.J., Hong, S.J., Yang, Z. et al. (2011). Development and clinical evaluation of a rapid serodiagnostic test for toxoplasmosis of cats using recombinant SAG1 antigen. Korean Journal of Parasitology 49: 207-212. https://doi.org/10.3347/kjp.2011.49.3.207

Costa, J.M., Alanio, A., Moukoury, S., Clairet, V., Debruyne, M., Poveda, J.D. \& Bretagne, S. (2013). Direct genotyping of Toxoplasma gondii from amniotic fluids based on B1 gene polymorphism using minisequencing analysis. $B M C$ Infectious Diseases 13: 552. http://www.biomedcentral.com/ $1471-2334 / 13 / 552$ 
Costa, J.M., Cabaret, O., Moukoury, S. \& Bretagne, S. (2011). Genotyping of the protozoan pathogen Toxoplasma gondii using high resolution melting analysis of the repeated B1 gene. Journal of Microbiological Methods 86: 357-363. https://doi.org/10.1016/j.mimet.2011.06.017

da Silva, P.C., Shiraishi, C.S., Silva, A.V., Gonçalves, G.F., Sant'Ana, D.M.G. \& Araújo, E.J.A. (2010). Toxoplasma gondii: A morphometric analysis of the wall and epithelial cells of pigs intestine. Experimental Parasitology 125: 380-383. https://doi.org/10.1016/j.exppara.2010.03.004

Dai, J., Jiang, M., Qu, L., Sun, L., Yang, Y., Gonf, L., Gong, R. \& Si, J. (2013). Toxoplasma gondii: Enzyme-linked immunosorbent assay based on a recombinant multi-epitope peptide for distinguishing recent from past infection in human sera. Experimental Parasitology 133: 95-100. https://doi.org/ 10.1016/j.exppara.2012.10.016

Dai, J., Jiang, M., Wang, Y., Qu, L., Gong, R. \& Si, J. (2012). Evaluation of a recombinant multiepitope peptide for serodiagnosis of Toxoplasma gondii infection. Clinical and Vaccine Immunology 19: 338-342. https://doi.org/10.1128/ CVI.05553-11

de Ory, F., Casas, I., Domingo, C.J. \& Echevarría, J. (1995). Application of fluoroimmunoassay to the identification of low avidity specific IgG against pathogenic human viruses and Toxoplasma gondii. Clinical and Diagnostic Virology 3: 323-332. https://doi.org/10.1016/0928-0197(94)00045-V

Deksne, G., Ligere, B., Šneidere, A. \& Jokelainen, P. (2017). Seroprevalence and factors associated with Toxoplasma gondii infections in sheep in Latvia: Latvian dark headed sheep breed associated with higher seroprevalence. Vector-Borne and Zoonotic Diseases 17: 478-482. https:// doi.org/10.1089/vbz.2016.2003

De-la-Torre, A. \& Gómez-Marín, J. (2020). Disease of the year 2019: Ocular toxoplasmosis in HIV-infected patients. Ocular Immunology and Inflammation 28: 1031-1039. https:// doi.org/10.1080/09273948.2020.1735450

Desmonts, G. \& Thulliez, P.H. (1985). The toxoplasma agglutination antigen as a tool for routine screening and diagnosis of toxoplasma infection in the mother and infant. Developments in Biological Standardization 62: 31.

Djokic, V., Fablet, C., Blaga, R., Rose, N., Perret, C., DjurkovicDjakovic, O., Boireau, P. \& Durand, B. (2016). Factors associated with Toxoplasma gondii infection in confined farrow to finish pig herds in western France: an exploratory study in 60 herds. Parasites \& Vectors 9: 466. https://doi.org/10.1186/s13071-016-1753-5

Dubey, J.P. \& Desmonts, G. (1987). Serological responses of equids fed Toxoplasma gondii oocysts. Equine Veterinary Journal 19: 337-339. https://doi.org/10.1111/j.2042-3306. 1987.tb01426.x

Dubey, J.P. (1993). Toxoplasma, Neospora, Sarcocystis, and other tissue cyst-forming coccidia of human and animals. Parasitic Protozoa 6: 1-56.

Dubey, J.P. (1997). Validation of the specificity of the modified agglutination test for toxoplasmosis in pigs. Veterinary Parasitology 71: 307-310. https://doi.org/10.1016/S03044017(97)00016-2

Dubey, J.P. (2006). Comparative infectivity of oocysts and bradyzoites of Toxoplasma gondii for intermediate (mice) and definitive (cats) hosts. Veterinary Parasitology 140: 6975. https://doi.org/10.1016/j.vetpar.2006.03.018

Dubey, J.P., Lindsay, D.S. \& Speer, C.A. (1998). Structures of Toxoplasma gondii tachyzoites, bradyzoites, and sporozoites and biology and development of tissue cysts. Clinical Microbiology Reviews 11: 267-299. https://doi.org/10.1128/ cmr.11.2.267
Dubey, J.P., Quirk, T., Pitt, J.A., Sundar, N., Velmurugan, G.V, Kwok, O.C.H., Leclair, D., Hill, R. \& Su, C. (2008). Isolation and genetic characterization of Toxoplasma gondii from raccoons (Procyon lotor), cats (Felis domesticus), striped skunk (Mephitis mephitis), black bear (Ursus americanus), and cougar (Puma concolor) from Canada. Journal of Parasitology 94: 42-45. https://doi.org/10.1645/GE-1349.1

Dubey, J.P., Sundar, N., Gennari, S.M., Minervino, A.H.H., Farias, N.A.R., Ruas, J.L., Santos, D.T.R.B., Cavalcante, G.T., Kwok, O.C.H. \& Su, C. (2007). Biologic and genetic comparison of Toxoplasma gondii isolates in free-range chickens from the northern para state and the southern state Rio Grande do sul, Brazil revealed highly diverse and distinct parasite populations. Veterinary Parasitology 143: 182-188. https:// doi.org/10.1016/j.vetpar.2006.08.024

Duong, H.D., Appiah-Kwarteng, C., Takashima, Y., Aye, K.M., Nagayasu, E. \& Yoshida, A. (2020). A novel luciferaselinked antibody capture assay (LACA) for the diagnosis of Toxoplasma gondii infection in chickens. Parasitology International 77: 102125. https://doi.org/10.1016/j.parint. 2020.102125

Edvinsson, B., Jalal, S., Nord, C.E., Pedersen, B.S. \& Evengård, B. (2004). DNA extraction and PCR assays for detection of Toxoplasma gondii. Apmis 112: 342-348. https://doi.org/ 10.1111/j.1600-0463.2004.apm1120604.x

Elsheikha, H.M., Marra, C.M. \& Zhu, X.Q. (2020). Epidemiology, pathophysiology, diagnosis, and management of cerebral toxoplasmosis. Clinical Microbiology Reviews 34: 1-28. https://doi.org/10.1128/CMR.00115-19

Fallahi, S., Kazemi, B., Seyyed tabaei, S.J., Bandehpour, M., Lasjerdi, Z., Taghipour, N., Zebardast, N., Nikmanesh, B., Omrani, V.F. \& Ebrahimzadeh, F. (2014a). Comparison of the RE and B1 gene for detection of Toxoplasma gondii infection in children with cancer. Parasitology International 63: 37-41. https://doi.org/10.1016/j.parint.2013.08.005

Fallahi, S., Mazar, Z.A., Ghasemian, M. \& Haghighi, A. (2015). Challenging loop-mediated isothermal amplification (LAMP) technique for molecular detection of Toxoplasma gondii. Asian Pacific Journal of Tropical Medicine 8: 366-372. https://doi.org/10.1016/S1995-7645(14)60345-X

Fallahi, S., Tabaei, S.J.S., Pournia, Y., Zebardast, N. \& Kazemi, B. (2014b). Comparison of loop-mediated isothermal amplification (LAMP) and nested-PCR assay targeting the $\mathrm{RE}$ and $\mathrm{B} 1$ gene for detection of Toxoplasma gondii in blood samples of children with leukaemia. Diagnostic Microbiology and Infectious Disease 79: 347-354. https://doi. org/10.1016/j.diagmicrobio.2014.02.014

Fernandes, S., Brilhante-Simões, P., Coutinho, T., Cardoso, L., Dubey, J.P. \& Lopes, A.P. (2019). Comparison of indirect and modified agglutination tests for detection of antibodies to Toxoplasma gondii in domestic cats. Journal of Veterinary Diagnostic Investigation 31: 774-777. https://doi.org/10.1177/ 1040638719868753

Ferra, B., Holec-Gasior, L. \& Grazlewska, W. (2020b). Toxoplasma gondii recombinant antigens in the serodiagnosis of toxoplasmosis in domestic and farm animals. Animals 10: 1245. https://doi.org/10.3390/ani10081245

Ferra, B., Holec-Gasior, L. \& Kur, J. (2015a). Serodiagnosis of Toxoplasma gondii infection in farm animals (horses, swine, and sheep) by enzyme-linked immunosorbent assay using chimeric antigens. Parasitology International 64: 288294. https://doi.org/10.1016/j.parint.2015.03.004 
Ferra, B., Holec-Gasior, L. \& Kur, J. (2015b). A new Toxoplasma gondii chimeric antigen containing fragments of SAG2, GRA1, and ROP1 proteins impact of immunodominant sequences size on its diagnostic usefulness. Parasitology Research 114: 3291-3299. https://doi.org/10.1007/s00436015-4552-6

Ferra, B., Holec-Gasior, L., Gatkowska, J., Dziadek, B. \& Dzitko, K. (2020a). Toxoplasma gondii recombinant antigen AMA1: Diagnostic utility of protein fragments for the detection of IgG and IgM antibodies. Pathogens 9: 43. https://doi.org/ 10.3390/pathogens9010043

Ferreira, A., Vitor, R.W.A., Carneiro, A.C.A.V, Brandão, G.P. \& Melo, M.N. (2004). Genetic variability of Brazilian Toxoplasma gondii strains detected by random amplified polymorphic DNA-polymerase chain reaction (RAPD-PCR) and simple sequence repeat anchored-PCR (SSR-PCR). Infection, Genetics and Evolution 4: 131-142. https://doi.org/ 10.1016/j.meegid.2004.03.002

Fulton, J.D. \& Turk, J.L. (1959). Direct agglutination test for Toxoplasma gondii. Lancet 2: 1068-1069. https://doi.org/ 10.1016/S0140-6736(59)91535-1

Gallas-Lindemann, C., Sotiriadou, I., Mahmoodi, M.R. \& Karanis, P. (2013). Detection of Toxoplasma gondii oocysts in different water resources by loop mediated isothermal amplification (LAMP). Acta Tropica 125: 231-236. https:// doi.org/10.1016/j.actatropica.2012.10.007

Garcia-Réguet, N., Lebrun, M., Fourmaux, M.N., MercereauPuijalon, O., Mann, T., Beckers, C.J.M., Samyn, B., Beeumen, J., Bout, D. \& Dubremetz, J.F. (2000). The microneme protein MIC3 of Toxoplasma gondii is a secretory adhesin that binds to both the surface of the host cells and the surface of the parasite. Cellular Microbiology 2: 353-364. https://doi. org/10.1046/j.1462-5822.2000.00064.x

Gazzonis, A.L., Villa, L., Lubian, E., Ressegotti, S., Grilli, G., Raimondi, S., Zanzani, S.A. \& Manfredi, M.T. (2021). Molecular survey on Toxoplasma gondii and Neospora caninum infection in wild birds of prey admitted to recovery centers in northern italy. Microorganisms 9: 736. https:// doi.org/10.3390/microorganisms9040736

Ge, W., Sun, H., Wang, Z., Xu, P., Wang, W., Mu, G., Wei, F. \& Liu, Q. (2014). Prevalence and genotype of Toxoplasma gondii infection in cattle from Jilin province, Northeastern China. Vector-Borne and Zoonotic Diseases 14: 399-402. https:// doi.org/10.1089/vbz.2013.1516

Ghazzay, M.H., Al-Kelaby, K.K.A., Al-Hilli, E.S.A.L.I. \& Hadi, N.R. (2020). Diagnosis of toxoplasmosis in pregnant women using enzyme immunoassay and nested real time PCR in Al-Najaf city/Iraq. International Journal of Pharmaceutical Research 12:140-147. https://doi.org/10.31838/ijpr/2020. 12.02.0022

Golkar, M., Azadmanesh, K., Khalili, G., Khoshkholgh-Sima, B., Babaie, J., Mercier, C., Brenier-Pinchart, M.P., FrickerHidalgo, H., Pelloux, H. \& Cesbron-Delauw, M.F. (2008). Serodiagnosis of recently acquired Toxoplasma gondii infection in pregnant women using enzyme linked immunosorbent assays with a recombinant dense granule GRA6 protein. Diagnostic Microbiology and Infectious Disease 61: 31-39. https://doi.org/10.1016/j.diagmicrobio. 2007.09.003

Gomes, D.F.C., Krawczak, F.S., Oliveira, C.H.S., Júnior, Á.F., Fernandes, É.K.K., Lopes, W.D.Z., Sevá, A.P. \& Gennari, S.M. (2020). Toxoplasma gondii in cattle in Brazil: A review. Revista Brasileira de Parasitologia Veterinaria 29: 1-16. https://doi.org/ 10.1590/s1984-29612019106
Gomez, C.A., Budvytyte, L.N., Press, C., Zhou, L., McLeod, R., Maldonado, Y., Montoya, J.G. \& Contopoulos-loannidis, D.G. (2018). Evaluation of three point of care tests for detection of Toxoplasma immunoglobulin IgG and IgM in the United States: proof of concept and challenges. Open Forum Infectious Diseases 5: 215. https://doi.org/10.1093/ ofid/ofy 215

Greninger, A.L. (2018). The challenge of diagnostic metagenomics. Expert Review of Molecular Diagnostics 18: 605615. https://doi.org/10.1080/14737159.2018.1487292

Grzybowski, M.M., Gatkowska, J.M., Dziadek, B., Dzitko, K. \& Dlugoñska, H. (2015). Human toxoplasmosis: a comparative evaluation of the diagnostic potential of recombinant Toxoplasma gondii ROP5 and ROP18 antigens. Journal of Medical Microbiology 64: 1201-1207. https:// doi.org/10.1099/jmm.0.000148

Gutierrez, J., O'Donovan, J., Williams, E., Proctor, A., Brady, C., Marques, P.X., Worrall, S., Nally, J.E., McElroy, M., Bassett, $\mathrm{H}$. et al. (2010). Detection and quantification of Toxoplasma gondii in ovine maternal and foetal tissues from experimentally infected pregnant ewes using real-time PCR. Veterinary Parasitology 172: 8-15. https://doi.org/ 10.1016/j.vetpar.2010.04.035

Habibi, G.R., Imani, A.R., Gholami, M.R., Hablolvarid, M.H., Behroozikhah, A.M., Lotfi, M., Kamalzade, M., Najjar, E., Esmaeil-Nia, K. \& Bozorgi, S. (2012). Detection and identification of Toxoplasma gondii type one infection in sheep aborted fetuses in qazvin province of Iran. Iranian Journal of Parasitology 7: 64.

Hajissa, K., Zakaria, R., Suppian, R. \& Mohamed, Z. (2015). Design and evaluation of a recombinant multi-epitope antigen for serodiagnosis of Toxoplasma gondii infection in humans. Parasites and Vectors 8: 315. https://doi.org/ 10.1186/s13071-015-0932-0

Hajissa, K., Zakaria, R., Suppian, R. \& Mohamed, Z. (2017). An evaluation of a recombinant multiepitope based antigen for detection of Toxoplasma gondii specific antibodies. BMC Infectious Diseases 17: 807. https://doi.org/10.1186/s12879017-2920-9

Halleyantoro, R., Andriyani, Y., Sari, I.P. \& Kurniawan, A. (2019). Nested PCR methods for detection Toxoplasma gondii B1 gene in cerebrospinal fluid of HIV patients. Journal of Biomedicine and Translational Research 5: 62-66. https:// doi.org/10.14710/jbtr.v5i2.4840

Hamidinejat, H., Nabavi, L., Mayahi, M., Ghourbanpoor, M., Pourmehdi Borojeni, M., Norollahi Fard, S. \& Shokrollahi, M. (2014). Comparison of three diagnostic methods for the detection of Toxoplasma gondii in free range chickens. Tropical Biomedicine 31: 507-513.

Hanafiah, M., Helmi, T.Z., Sutriana, A., Priyowidodo, D. \& Fihiruddin, F. (2020). Cloning and expression of Toxoplasma gondii GRA 4 recombinant protein as a toxoplasmosis diagnostic kit candidate. Veterinary World 13: 2085. https:/ /doi.org/10.14202/vetworld.2020.2085-2091

Harrison, W.T. \& Hulette, C. (2017). Cerebral toxoplasmosis: a case report with correlation of radiographic imaging, surgical pathology, and autopsy findings. Academic Forensic Pathology 7: 494-501. https://doi.org/10.23907/ 2017.042

Hedman, K., Lappalainen, M., Söderlund, M. \& Hedman, L. (1993). Avidity of IgG in serodiagnosis of infectious diseases. Reviews in Medical Microbiology 4: 123-129. 
Herrero, L., Gracia, M.J., Pérez-Arquillué, C., Lázaro, R., Herrera, M., Herrera, A. \& Bayarri, S. (2016). Toxoplasma gondii: pig seroprevalence, associated risk factors and viability in fresh pork meat. Veterinary Parasitology 224: 52-59. https:// doi.org/10.1016/j.vetpar.2016.05.010

Hill, D.E., Chirukandoth, S., Dubey, J.P., Lunney, J.K. \& Gamble, H.R. (2006). Comparison of detection methods for Toxoplasma gondii in naturally and experimentally infected swine. Veterinary Parasitology 141: 9-17. https://doi.org/ 10.1016/j.vetpar.2006.05.008

Hiszczyñska-Sawicka, E., Brillowska-Da'browska, A., Da'abrowski, S., Pietkiewicz, H., Myjak, P. \& Kur, J. (2003). High yield expression and single step purification of Toxoplasma gondii SAG1, GRA1, and GRA7 antigens in Escherichia coli. Protein Expression and Purification 27: 150157. https://doi.org/10.1016/S1046-5928(02)00593-4

Hiszczyñska-Sawicka, E., Kur, J., Pietkiewicz, H., Holec, L., Ga'sior, A. \& Myjak, P. (2005). Efficient production of the Toxoplasma gondii GRA6, P35 and SAG2 recombinant antigens and their applications in the serodiagnosis of toxoplasmosis. Acta Parasitologica 50: 249-254.

Holec, L., Gasior, A., Brillowska-Dabrowska, A. \& Kur, J. (2008). Toxoplasma gondii: enzyme-linked immunosorbent assay using different fragments of recombinant microneme protein 1 (MIC1) for detection of immunoglobulin $G$ antibodies. Experimental Parasitology 119: 1-6. https://doi. org/10.1016/j.exppara.2007.12.002

Holec, L., Hiszczyñska-Sawicka, E., Gasior, A., BrillowskaDabrowska, A. \& Kur, J. (2007). Use of MAG1 recombinant antigen for diagnosis of Toxoplasma gondii infection in humans. Clinical and Vaccine Immunology 14: 220-225. https://doi.org/10.1128/CVI.00419-06

Holec-Gasior, L. \& Kur, J. (2010). Toxoplasma gondii: recombinant GRA5 antigen for detection of immunoglobulin $G$ antibodies using enzyme linked immunosorbent assay. Experimental Parasitology 124: 272-278. https://doi.org/ 10.1016/j.exppara.2009.10.010

Holec-Gasior, L. (2013). Toxoplasma gondii recombinant antigens as tools for serodiagnosis of human toxoplasmosis: Current status of studies. Clinical and Vaccine Immunology 20: 1343-1351. https://doi.org/10.1128/CVI.00117-13

Holec-Gasior, L., Ferra, B. \& Drapala, D. (2012a). MIC1-MAG1SAG1 chimeric protein, a most effective antigen for detection of human toxoplasmosis. Clinical and Vaccine Immunology 19: 1977-1979. https://doi.org/10.1128/CVI. 00452-12

Holec Gasior, L., Ferra, B. \& Grazlewska, W. (2019). Toxoplasma gondii tetravalent chimeric proteins as novel antigens for detection of specific immunoglobulin $\mathrm{G}$ in sera of small ruminants. Animals 9: 1146 https://doi.org/10.3390/ ani9121146

Holec-Gasior, L., Ferra, B., Drapala, D., Lautenbach, D. \& Kur, J. (2012b). A new MIC1-MAG1 recombinant chimeric antigen can be used instead of the Toxoplasma gondii lysate antigen in serodiagnosis of human toxoplasmosis. Clinical and Vaccine Immunology 19: 57-63. https://doi.org/10.1128/ CVI.05433-11

Holec-Gasior, L., Ferra, B., Hiszczyñska-Sawicka, E. \& Kur, J. (2014). The optimal mixture of Toxoplasma gondii recombinant antigens (GRA1, P22, ROP1) for diagnosis of ovine toxoplasmosis. Veterinary Parasitology 206: 146-152. https://doi.org/10.1016/j.vetpar.2014.09.018

Holec-Gasior, L., Kur, J. \& Hiszczyñska-Sawicka, E. (2009). GRA2 and ROP1 recombinant antigens as potential markers for detection of Toxoplasma gondii-specific immunoglobulin $\mathrm{G}$ in humans with acute toxoplasmosis. Clinical and Vaccine Immunology 16: 510-514. https://doi.org/10.1128/CVI.0034108
Holec-Gasior, L., Kur, J., Hiszczynska-Sawicka, E., Drapala, D., Dominiak-Górski, B. \& Pejsak, Z. (2010). Application of recombinant antigens in serodiagnosis of swine toxoplasmosis and prevalence of Toxoplasma gondii infection among pigs in Poland. Polish Journal of Veterinary Sciences 13: 457-464.

Howe, D.K. \& Sibley, L.D. (1995). Toxoplasma gondii comprises three clonal lineages: correlation of parasite genotype with human disease. Journal of Infectious Diseases 172: 15611566. https://doi.org/10.1093/infdis/172.6.1561

Hu, X., Pan, C.W., Li, Y.F., Wang, H. \& Tan, F. (2012). Urine sample used for detection of Toxoplasma gondii infection by loop mediated isothermal amplification (LAMP). Folia Parasitologica 59: 21-26. https://doi.org/10.14411/fp.2012.004

Hu, Z., Weng, X., Xu, C., Lin, Y., Cheng, C., Wei, H. \& Chen, W. (2018). Metagenomic next generation sequencing as a diagnostic tool for toxoplasmic encephalitis. Annals of Clinical Microbiology and Antimicrobials 17: 4-9. https:// doi.org/10.1186/s12941-018-0298-1

Huang, X., Xuan, X., Hirata, H., Yokoyama, N., Xu, L., Suzuki, N. \& Igarashi, I. (2004). Rapid immunochromatographic test using recombinant SAG2 for detection of antibodies against Toxoplasma gondii in cats. Journal of Clinical Microbiology 42: 351-353. https://doi.org/10.1128/JCM. 42.1.351-353.2004

Ismael, A.B., Sekkai, D., Collin, C., Bout, D. \& Mévélec, M.N. (2003). MIC3 gene of Toxoplasma gondii is a novel potent vaccine candidate against toxoplasmosis. Infection and Immunity 71: 6222-6228. https://doi.org/10.1128/IAI. 71.11.6222-6228.2003

Jacobs, D., Dubremetz, J.F., Loyens, A., Bosman, F. \& Saman, E. (1998). Identification and heterologous expression of a new dense granule protein (GRA7) from Toxoplasma gondii. Molecular and Biochemical Parasitology 91: 237-249. https:// doi.org/10.1016/S0166-6851(97)00204-1

Jacobs, D., Vercammen, M. \& Saman, E. (1999). Evaluation of recombinant dense granule antigen 7 (GRA7) of Toxoplasma gondii for detection of immunoglobulin $\mathrm{G}$ antibodies and analysis of a major antigenic domain. Clinical and Diagnostic Laboratory Immunology 6: 24-29. https://doi.org/10.1128/ CDLI.6.1.24-29.1999

Jacobs, L. \& Lunde, M.N. (1957). A hemagglutination test for toxoplasmosis. The Journal of Parasitology 43: 308-314. https://doi.org/10.2307/3274354

Jalallou, N., Bandepour, M., Khazan, H., Haghighi, A., Abdollahi, S.H. \& Kazemi, B. (2010). Recombinant SAG1 antigen to detect Toxoplasma gondii specific immunoglobulin $\mathrm{G}$ in human sera by ELISA test. Iranian Journal of Parasitology 5: 1-9.

Jex, A.R., Smith, H. V, Monis, P.T., Campbell, B.E. \& Gasser, R.B. (2008). Cryptosporidium-biotechnological advances in the detection, diagnosis and analysis of genetic variation. Biotechnology Advances 26: 304-317. https://doi.org/10.1016/ j.biotechadv.2008.02.003

Jiang, T., Gong, D., Ma, L. an, Nie, H., Zhou, Y., Yao, B. \& Zhao, J. (2008). Evaluation of a recombinant MIC3 based latex agglutination test for the rapid serodiagnosis of Toxoplasma gondii infection in swines. Veterinary Parasitology 158: 51-56. https://doi.org/10.1016/j.vetpar.2008.07.035

Jiang, W., Liu, Y., Chen, Y., Yang, Q., Chun, P., Yao, K., Han, X., Wang, S., Yu, S. \& Liu, Y. (2015). A novel dynamic flow immunochromatographic test (DFICT) using gold nanoparticles for the serological detection of Toxoplasma gondii infection in dogs and cats. Biosensors and Bioelectronics 72: 133-139. https://doi.org/10.1016/j.bios.2015.04.035 
Johnson, A.M., Roberts, H. \& Tenter, A.M. (1992). Evaluation of a recombinant antigen ELISA for the diagnosis of acute toxoplasmosis and comparison with traditional antigen ELISAs. Journal of Medical Microbiology 37: 404-409. https:// doi.org/10.1099/00222615-37-6-404

Jones, C.D., Okhravi, N., Adamson, P., Tasker, S. \& Lightman, S. (2000). Comparison of PCR detection methods for B1, P30, and $18 \mathrm{~S}$ rDNA genes of $T$. gondii in aqueous humor. Investigative Ophthalmology and visual science 41: 634-644.

Jones, J.L., Kruszon-Moran, D., Wilson, M., McQuillan, G., Navin, T. \& McAuley, J.B. (2001). Toxoplasma gondii infection in the United States: seroprevalence and risk factors. American Journal of Epidemiology 154: 357-365. https://doi. org/10.1093/aje/154.4.357

Karakavuk, M., Can, H., Selim, N., Yesilsiraz, B., Atli, E., Sahar, E.A., Demir, F., Gül, A., Özdemir, H.G., Alan, N. et al. (2021). Investigation of the role of stray cats for transmission of toxoplasmosis to humans and animals living in Izmir, Turkey. Journal of Infection in Developing Countries 15: 155162. https://doi.org/10.3855/jidc.13932

Kareshk, A.T., Oliaee, R.T., Mahmoudvand, H., Keyhani, A., Mohammadi, M.A., Bamorovat, M., Hajhosseini, M.A. \& Zia-Ali, N. (2018). The first survey of isolation and molecular typing of Toxoplasma gondii by bioassay and PCR method in BALB/C mice in camels (Camelus dromedarius) from eastern Iran. Iranian Journal of Parasitology 13: 382-391.

Khalili, P.E., Riazi-Esfahani, H., Ebrahimiadib, N., Esteghamati, V.Z. \& Zarei, M. (2021). Acquired Immunodeficiency Syndrome Presented as Atypical Ocular Toxoplasmosis. Case Reports in Ophthalmological Medicine 2021: 5512408. https://doi.org/10.1155/2021/5512408

Khan, A., Taylor, S., Su, C., Mackey, A.J., Boyle, J., Cole, R., Glover, D., Tang, K., Paulsen, I.T., Berriman, M. et al. (2005). Composite genome map and recombination parameters derived from three archetypal lineages of Toxoplasma gondii. Nucleic Acids Research 33: 2980-2992. https://doi.org/ 10.1093/nar/gki604

Khan, A.H. \& Noordin, R. (2020). Serological and molecular rapid diagnostic tests for toxoplasma infection in humans and animals. European Journal of Clinical Microbiology and Infectious Diseases 39: 19-30. https://doi.org/10.1007/s10096019-03680-2

Khanaliha, K., Motazedian, M.H., Sarkari, B., Bandehpour, M., Sharifnia, Z. \& Kazemi, B. (2012). Expression and purification of P43 Toxoplasma gondii surface antigen. Iranian Journal of Parasitology 7: 48.

Kim, J.Y., Kwak, Y.S., Lee, I.Y. \& Yong, T.S. (2020). Molecular Detection of Toxoplasma gondii in haemaphysalis ticks in Korea. The Korean Journal of Parasitology 58: 327-331. https:/ /doi.org/10.3347/kjp.2020.58.3.327

Kissinger, J.C., Gajria, B., Li, L., Paulsen, I.T. \& Roos, D.S. (2003). ToxoDB: Accessing the Toxoplasma gondii genome. Nucleic Acids Research 31: 234-236. https://doi.org/10.1093/nar/ gkg072

Kodym, P. (2001). Toxoplasma in the Czech Republic 1923-1999: first case to widespread outbreak. International Journal of Parasitology 31: 125-132.

Kotresha, D. \& Noordin, R. (2010). Recombinant proteins in the diagnosis of toxoplasmosis. Apmis 118: 529-542. https://doi.org/10.1111/j.1600-0463.2010.02629.x

Kotresha, D., Poonam, D., Hafiznur, M.Y., Saadatnia, G., Nurulhasanah, O., Sabariah, O., Tan, S.Y., Izzati Zahidah, A.K. \& Rahmah, N. (2012). Recombinant proteins from new constructs of SAG1 and GRA7 sequences and their usefulness to detect acute toxoplasmosis. Tropical Biomedicine 29: 129-137.
Lago, E.G., Baldisserotto, M., Filho, H.J.R., Santiago, D. \& Jungblut, R. (2007). Agreement between ultrasonography and computed tomography in detecting intracranial calcifications in congenital toxoplasmosis. Clinical Radiology 62: 1004-1011. https://doi.org/10.1016/j.crad. 2007.05.001

Lass, A., Szostakowska, B., Korzeniewski, K. \& Karanis, P. (2017). The first detection of Toxoplasma gondii DNA in environmental air samples using gelatine filters, real time PCR and loop mediated isothermal (LAMP) assays: qualitative and quantitative analysis. Parasitology 144: 1791-1801. https://doi.org/10.1017/S0031182017001172

Lau, Y.L. \& Fong, M.Y. (2008). Toxoplasma gondii: serological characterization and immunogenicity of recombinant surface antigen 2 (SAG2) expressed in the yeast Pichia pastoris. Experimental Parasitology 119: 373-378. https:// doi.org/10.1016/j.exppara.2008.03.016

Lau, Y.L., Fong, M.Y., Idris, M.M. \& Ching, X.T. (2012). Cloning and expression of Toxoplasma gondii dense granule antigen 2 (GRA2) gene by Pichia pastoris. Southeast Asian Journal of Tropical Medicine and Public Health 43: 10-16.

Lau, Y.L., Hasan, M.T., Thiruvengadam, G., Idris, M.M. \& Init, I. (2010a). Cloning and expression of Toxoplasma gondii dense granular protein 4 (GRA4) in Pichia pastoris. Tropical Biomedicine 27: 525-533.

Lau, Y.L., Meganathan, P., Sonaimuthu, P., Thiruvengadam, G., Nissapatorn, V. \& Chen, Y. (2010b). Specific, sensitive, and rapid diagnosis of active toxoplasmosis by a loop mediated isothermal amplification method using blood samples from patients. Journal of Clinical Microbiology 48: 3698-3702. https://doi.org/10.1128/JCM.00462-10

Lau, Y.L., Thiruvengadam, G., Lee, W.W. \& Fong, M.Y. (2011). Immunogenic characterization of the chimeric surface antigen 1 and 2 (SAG1/2) of Toxoplasma gondii expressed in the yeast Pichia pastoris. Parasitology Research 109: 871. https://doi.org/10.1007/s00436-011-2315-6

Lavinsky, D., Romano, A., Muccioli, C. \& Belfort, R. (2012). Imaging in ocular toxoplasmosis. International Ophthalmology Clinics 52: 131-143. https://doi.org/10.1097/ IIO.0b013e318265fd78

Li, S., Maine, G., Suzuki, Y., Araujo, F.G., Galvan, G., Remington, J.S. \& Parmley, S. (2000). Serodiagnosis of recently acquired Toxoplasma gondii infection with a recombinant antigen. Journal of Clinical Microbiology 38: 179-184. https://doi.org/ 10.1128/JCM.38.1.179-184.2000

Lilly, E.L. \& Wortham, C.D. (2013). High prevalence of Toxoplasma gondii oocyst shedding in stray and pet cats (Felis catus) in Virginia, United States. Parasites and Vectors 6: 2-5. https://doi.org/10.1186/1756-3305-6-266

Liu, Q., Wang, Z.D., Huang, S.Y. \& Zhu, X.Q. (2015). Diagnosis of toxoplasmosis and typing of Toxoplasma gondii. Parasites and Vectors 8: 292. https://doi.org/10.1186/s13071-015-09026

Liu, X.Y., Wang, Z.D., El-Ashram, S. \& Liu, Q. (2019). Toxoplasma gondii oocyst driven infection in pigs, chickens and humans in northeastern China. BMC Veterinary Research 15: 4-10. https://doi.org/10.1186/s12917-019-2121-4

Lorenzi, H., Khan, A., Behnke, M.S., Namasivayam, S., Swapna, L.S., Hadjithomas, M., Karamycheva, S., Pinney, D., Brunk, B.P. \& Ajioka, J.W. (2016). Local admixture of amplified and diversified secreted pathogenesis determinants shapes mosaic Toxoplasma gondii genomes. Nature Communications 7: 10147. https://doi.org/10.1038/ ncomms10147 
Lu, B., Wu, S., Shi, Y., Zhang, R., Zou, L., Gao, S., Lin, M. \& Zhou, Y. (2006). Toxoplasma gondii: expression pattern and detection of infection using full length recombinant P35 antigen. Experimental Parasitology 113: 83-90. https:// doi.org/10.1016/j.exppara.2005.12.014

Luo, J., Sun, H., Zhao, X., Wang, S., Zhuo, X., Yang, Y., Chen, X., Yao, C. \& Du, A. (2018). Development of an immunochromatographic test based on monoclonal antibodies against surface antigen 3 (TgSAG3) for rapid detection of Toxoplasma gondii. Veterinary Parasitology 252: 52-57. https:/ /doi.org/10.1016/j.vetpar.2018.01.015

Lv, Q.Y., Zheng, H.L., Yang, W.H. \& Liu, G.H. (2021). Molecular Detection of Toxoplasma gondii and Neospora caninum in domestic ducks in Hunan province, China. Frontiers in Veterinary Science 8: 6-11. https://doi.org/10.3389/ fvets.2021.649603

Mahalakshmi, B., Therese, K.L., Madhavan, H.N. \& Biswas, J. (2006). Diagnostic value of specific local antibody production and nucleic acid amplification technique nested polymerase chain reaction ( $\mathrm{APCR}$ ) in clinically suspected ocular toxoplasmosis. Ocular Immunology and Inflammation 14: 105-112. https://doi.org/10.1080/ 09273940500545692

Marques, C.S., Sousa, S., Castro, A. \& Costa, J.M.C. (2020). Detection of Toxoplasma gondii oocysts in fresh vegetables and berry fruits. Parasites and Vectors 13: 180. https:// doi.org/10.1186/s13071-020-04040-2

Martinez, E., Carmelo, E., Alonso, R., Ortega, A., Pinero, J., Castillo, A. \& Valladares, B. (2003). Development of a rapid polymerase chain reaction ELISA assay using polystyrene beads for the detection of Toxoplasma gondii DNA. Letters in Applied Microbiology 36: 30-34. https://doi.org/10.1046/ j.1472-765X.2003.01258.x

Masamed, R., Meleis, A., Lee, E.W. \& Hathout, G.M. (2009). Cerebral toxoplasmosis: case review and description of a new imaging sign. Clinical Radiology 64: 560-563. https:// doi.org/10.1016/j.crad.2008.09.016

Matta, S.K., Rinkenberger, N., Dunay, I.R. \& Sibley, L.D. (2021). Toxoplasma gondii infection and its implications within the central nervous system. Nature Reviews Microbiology 19: 467-480. https://doi.org/10.1038/s41579-021-00518-7

McGovern, K.E. \& Wilson, E.H. (2013). Dark side illuminated: Imaging of Toxoplasma gondii through the decades. Parasites and Vectors 6: 334. https://doi.org/10.1186/1756-3305-6-334

Meek, B., Diepersloot, R.J., Gool, T., Speijer, D. \& Peek, R. (2003). IgM recognition of recombinant Toxoplasma gondii antigens by sera of acutely or latently infected humans. Diagnostic Microbiology and Infectious Disease 45: 45-52. https://doi.org/10.1016/S0732-8893(02)00476-5

Meroni, V., Genco, F., Tinelli, C., Lanzarini, P., Bollani, L., Stronati, M. \& Petersen, E. (2009). Spiramycin treatment of Toxoplasma gondii infection in pregnant women impairs the production and the avidity maturation of $T$. gondiispecific immunoglobulin $\mathrm{G}$ antibodies. Clinical and Vaccine Immunology 16: 1517-1520. https://doi.org/10.1128/ CVI.00253-09

Mikita, K., Maeda, T., Ono, T., Miyahira, Y., Asai, T. \& Kawana, A. (2013). The utility of cerebrospinal fluid for the molecular diagnosis of toxoplasmic encephalitis. Diagnostic Microbiology and Infectious Disease 75: 155-159. https://doi.org/10.1016/j.diagmicrobio.2012.10.015

Mohamed, K. (2020). Toxoplasmosis in humans and animals in Saudi Arabia: A systematic review. Journal of Infection in Developing Countries 14: 800-811. https://doi.org/10.3855/ jidc.12648
Moncada, P.A. \& Montoya, J.G. (2012). Toxoplasmosis in the fetus and newborn: an update on prevalence, diagnosis and treatment. Expert Review of Anti-Infective Therapy 10: 815-828. https://doi.org/10.1586/eri.12.58

Mori, Y. \& Notomi, T. (2009). Loop mediated isothermal amplification (LAMP): A rapid, accurate, and cost-effective diagnostic method for infectious diseases. Journal of Infection and Chemotherapy 15: 62-69. https://doi.org/ 10.1007/s10156-009-0669-9

Mose, J.M., Kagira, J.M., Karanja, S.M., Ngotho, M., Kamau, D.M., Njuguna, A.N. \& Maina, N.W. (2016). Detection of natural Toxoplasma gondii infection in chicken in thika region of Kenya using nested polymerase chain reaction. BioMed Research International 2016: 7589278 https://doi.org/ 10.1155/2016/7589278

Mousavi, M., Saravani, R., Modrek, M.J., Shahrakipour, M. \& Sekandarpour, S. (2016). Detection of Toxoplasma gondii in diabetic patients using the nested PCR assay via RE and B1 genes. Jundishapur Journal of Microbiology 9: e29493. https://doi.org/10.5812/jjm.29493

Murata, F.H.A., Previato, M., Frederico, F.B., Barbosa, A.P., Nakashima, F., Faria, G.M., Silveira Carvalho, A.P., Meira Strejevitch, C.S., Pereira-Chioccola, V.L., Castiglioni, L. et al. (2020). Evaluation of serological and molecular tests used for the identification of Toxoplasma gondii infection in patients treated in an ophthalmology clinic of a public health service in São Paulo State, Brazil. Frontiers in Cellular and Infection Microbiology 9: 472. https://doi.org/10.3389/ fcimb.2019.00472

Nakashima, F., Pardo, V.S., Miola, M.P., Murata, F.H.A., Paduan, N., Longo, S.M., Brandão-de-Mattos, C.C., PereiraChioccola, V.L., Ricci, O. \& Mattos, L.C. (2020). Serum IgG Anti-Toxoplasma gondii antibody concentrations do not correlate nested pcr results in blood donors. Frontiers in Cellular and Infection Microbiology 9: 461. https://doi.org/ 10.3389/fcimb.2019.00461

Ngui, R., Hassan, N.A., Chang, L.Y., Teh, S.J.C., Chua, K.H., Kee, B.P., Hoe, S.Z. \& Lim, Y.A.L. (2020). Toxoplasma gondii infection among selected indigenous community in Sarawak, East Malaysia. Tropical Biomedicine 37: 155-164.

Nigro, M., Gutierrez, A., Hoffer, A.M., Clemente, M., Kaufer, F., Carral, L., Martin, V., Guarnera, E.A. \& Angel, S.O. (2003). Evaluation of Toxoplasma gondii recombinant proteins for the diagnosis of recently acquired toxoplasmosis by an immunoglobulin $\mathrm{G}$ analysis. Diagnostic Microbiology and Infectious Disease 47: 609-613. https://doi.org/10.1016/S07328893(03)00156-1

Nockemann, S., Dlugonska, H., Henrich, B., Kitzerow, A. \& Däubener, W. (1998). Expression, characterization and serological reactivity of a $41 \mathrm{kDa}$ excreted-secreted antigen (ESA) from Toxoplasma gondii. Molecular and Biochemical Parasitology 97: 109-121. https://doi.org/10.1016/ S0166-6851(98)00138-8

Onduru, O.G. \& Aboud, S. (2021). Prevalence and risk factors for typical signs and symptoms of toxoplasmosis in children born to at risk pregnant women attending prenatal care in Temeke district, Tanzania. Scientific African 11: e00690. https://doi.org/10.1016/j.sciaf.2020.e00690

Opsteegh, M., Dam-Deisz, C., De-Boer, P., De-Craeye, S., Faré, A., Hengeveld, P., Luiten, R., Schares, G., Solt-Smits, C. \& Verhaegen, B. (2020). Methods to assess the effect of meat processing on viability of Toxoplasma gondii: towards replacement of mouse bioassay by in vitro testing. International Journal for Parasitology 50: 357-369. https://doi.org/ 10.1016/j.ijpara.2020.04.001 
Opsteegh, M., Langelaar, M., Sprong, H., Hartog, L., De-Craeye, S., Bokken, G., Ajzenberg, D., Kijlstra, A. \& der-Giessen, J.V. (2010). Direct detection and genotyping of Toxoplasma gondii in meat samples using magnetic capture and PCR. International Journal of Food Microbiology 139: 193-201. https:/ /doi.org/10.1016/j.ijfoodmicro.2010.02.027

Opsteegh, M., Maas, M., Schares, G. \& Giessen, J.V.D. (2016). Relationship between seroprevalence in the main livestock species and presence of Toxoplasma gondii in meat (GP/EFSA/BIOHAZ/2013/01) An extensive literature review. Final report. EFSA Supporting Publications 13: 996E. https://doi.org/10.2903/sp.efsa.2016.EN-996

Pal, M., Alem, B., Gari, G. \& Tuli, G. (2014). Toxoplasmosis in animals and humans, its diagnosis, epidemiology and control. International Journal of Livestock Research 4: 1-10. https://doi.org/10.5455/ijlr.20140608054253

Paraboni, M.L.R., Costa, D.F., Silveira, C., Gava, R., PereiraChioccola, V.L., Belfort, R. \& Commodaro, A.G. (2020). A new strain of Toxoplasma gondii circulating in southern Brazil. Journal of Parasitic Diseases 44: 248-252. https:// doi.org/10.1007/s12639-019-01155-x

Pepe, P., Bosco, A., Capuano, F., Baldi, L., Giordano, A., Mancusi, A., Buonanno, M., Morena, L., Pinto, R., Sarnelli, P. et al. (2021). Towards an Integrated Approach for Monitoring toxoplasmosis in Southern Italy. Animals 11: 1949. https:/ /doi.org/10.3390/ani11071949

Pietkiewicz, H., Hiszczyñska-Sawicka, E., Kur, J., Petersen, E., Nielsen, H.V., Stankiewicz, M., Andrzejewska, I. \& Myjak, P. (2004). Usefulness of Toxoplasma gondii-specific recombinant antigens in serodiagnosis of human toxoplasmosis. Journal of Clinical Microbiology 42: 1779-1781. https://doi.org/10.1128/JCM.42.4.1779-1781.2004

Pinon, J.M., Toubas, D., Marx, C., Mougeot, G., Bonnin, A., Bonhomme, A., Villaume, M., Foudrinier, F. \& Lepan, H. (1990). Detection of specific immunoglobulin $E$ in patients with toxoplasmosis. Journal of Clinical Microbiology 28: 17391743. https://doi.org/10.1128/jcm.28.8.1739-1743.1990

Qu, D., Zhou, H., Han, J., Tao, S., Zheng, B., Chi, N., Su, C. \& Du, A. (2013). Development of reverse transcription loop mediated isothermal amplification (RT-LAMP) as a diagnostic tool of Toxoplasma gondii in pork. Veterinary Parasitology 192: 98-103. https://doi.org/10.1016/j.vetpar. 2012.10.010

Rajendran, C., Keerthana, C.M., Anilakumar, K.R., Satbige, A.S. \& Gopal, S. (2018). Development of B1 Nested PCR for assessing the prevalence of zoonotic protozoan disease agent Toxoplasma gondii among Food Animals from Karnataka state, Southern India. Journal of Microbiology and Laboratory Science 1: 101.

Redlich, A. \& Müller, W.A. (1998). Serodiagnosis of acute toxoplasmosis using a recombinant form of the dense granule antigen GRA6 in an enzyme linked immunosorbent assay. Parasitology Research 84: 700-706. https:// doi.org/10.1007/s004360050473

Reischl, U., Bretagne, S., Krüger, D., Ernault, P. \& Costa, J.M. (2003). Comparison of two DNA targets for the diagnosis of toxoplasmosis by real time PCR using fluorescence resonance energy transfer hybridization probes. $B M C$ Infectious Diseases 3: 7. https://doi.org/10.1186/1471-23343-7

Reiter-Owona, I., Petersen, E., Joynson, D., Aspöck, H., Dardé, M.L., Disko, R., Dreazen, O., Dumon, H., Grillo, R., Gross, U. et al. (1999). The past and present role of the SabinFeldman dye test in the serodiagnosis of toxoplasmosis. Bulletin of the World Health Organization 77: 929-935.
Remington, J.S., Thulliez, P. \& Montoya, J.G. (2004). Recent developments for diagnosis of toxoplasmosis. Journal of Clinical Microbiology 42: 941-945. https://doi.org/10.1128/ JCM.42.3.941-945.2004

Retmanasari, A., Widartono, B.S., Wijayanti, M.A. \& Artama, W.T. (2017). Prevalence and risk factors for toxoplasmosis in middle java, Indonesia. EcoHealth 14: 162-170. https:// doi.org/10.1007/s10393-016-1198-5

Riaz, F., Rashid, I., Akbar, H., Shehzad, W., Islam, S., Bajwa, A.A., Saeed, K. \& Ashraf, K. (2016). DNA amplification techniques for the detection of Toxoplasma gondii tissue cysts in meat producing animals: A narrative review article. Iranian Journal of Parasitology 11: 431-440.

Robert-Gangneux, F. \& Dardé, M.L. (2012). Epidemiology of and diagnostic strategies for toxoplasmosis. Clinical Microbiology Reviews 25: 264-296. https://doi.org/10.1128/ CMR.05013-11

Rorman, E., Zamir, C.S., Rilkis, I. \& Ben-David, H. (2006). Congenital toxoplasmosis prenatal aspects of Toxoplasma gondii infection. Reproductive Toxicology 21: 458-472. https:/ /doi.org/10.1016/j.reprotox.2005.10.006

Rostami, A., Karanis, P. \& Fallahi, S. (2018). Advances in serological, imaging techniques and molecular diagnosis of Toxoplasma gondii infection. Infection 46: 303-315. https://doi.org/10.1007/s15010-017-1111-3

Rostami, A., Riahi, S.M., Contopoulos-loannidis, D.G., Gamble, H.R., Fakhri, Y., Shiadeh, M.N., Foroutan, M., Behniafar, H., Taghipour, A., Maldonado, Y.A. et al. (2019). Acute toxoplasma infection in pregnant women worldwide: A systematic review and meta analysis. PLoS Neglected Tropical Diseases 13: e0007807. https://doi.org/10.1371/ journal.pntd.0007807

Rousseau, A., Carbona, S.L., Dumètre, A., Robertson, L.J., Gargala, G., Escotte-Binet, S., Favennec, L., Villena, I., Gérard, C. \& Aubert, D. (2018). Assessing viability and infectivity of foodborne and waterborne stages (cysts/ oocysts) of Giardia duodenalis, Cryptosporidium spp., and Toxoplasma gondii: A review of methods. Parasite 25: 14. https://doi.org/10.1051/parasite/2018009

Saadatnia, G. \& Golkar, M. (2012). A review on human toxoplasmosis. Scandinavian Journal of Infectious Diseases 44: 805-814. https://doi.org/10.3109/00365548.2012.693197

Sabin, A.B. \& Feldman, H.A. (1948). Dyes as microchemical indicators of a new immunity phenomenon affecting a protozoon parasite (Toxoplasma). Science 108: 660-663. https://doi.org/10.1126/science.108.2815.660

Sager, H., Gloor, M., Tenter, A., Maley, S., Hässig, M. \& Gottstein, B. (2003). Immunodiagnosis of primary Toxoplasma gondii infection in sheep by the use of a P30 IgG avidity ELISA. Parasitology Research 91: 171-174. https://doi.org/10.1007/ s00436-003-0964-9

Saha, S. \& Raghava, G.P.S. (2006). Prediction of continuous B cell epitopes in an antigen using recurrent neural network. Proteins: Structure, Function, and Bioinformatics 65: 40-48. https://doi.org/10.1002/prot.21078

Santana, S.S., Gebrim, L.C., Carvalho, F.R., Barros, H.S., Barros, P.C., Pajuaba, A.C.A.M., Messina, V., Possenti, A., Cherchi, S. \& Reiche, E. (2015). CCp5A protein from Toxoplasma gondii as a serological marker of oocyst-driven infections in humans and domestic animals. Frontiers in Microbiology 6: 1305. https://doi.org/10.3389/fmicb.2015.01305 
Santoro, M., Viscardi, M., Boccia, F., Borriello, G., Lucibelli, M.G., Auriemma, C., Anastasio, A., Veneziano, V., Galiero, G., Baldi, L. et al. (2020). Parasite load and strs genotyping of Toxoplasma gondii isolates from mediterranean mussels (Mytilus galloprovincialis) in southern Italy. Frontiers in Microbiology 11: 355. https://doi.org/10.3389/fmicb.2020. 00355

Saouros, S., Dou, Z., Henry, M., Marchant, J., Carruthers, V.B. \& Matthews, S. (2012). Microneme protein 5 regulates the activity of Toxoplasma subtilisin 1 by mimicking a subtilisin prodomain. Journal of Biological Chemistry 287: 36029-36040. https://doi.org/10.1074/jbc.M112.389825

Sardinha-Silva, A., Mendonça-Natividade, F.C., Pinzan, C.F., Lopes, C.D., Costa, D.L., Jacot, D., Fernandes, F.F., ZorzettoFernandes, A.L.V., Gay, N.J., Sher, A. et al. (2019). The lectin specific activity of Toxoplasma gondii microneme proteins 1 and 4 binds toll-like receptor 2 and $4 \mathrm{~N}$-glycans to regulate innate immune priming. PLoS Pathogens 15: e1007871. https://doi.org/10.1371/journal.ppat.1007871

Sarkari, B., Asgari, Q., Bagherian, N., Esfahani, S.A., Kalantari, M., Mohammadpour, I., Ashrafmansori, M., Amerinia, M. \& Sarvestani, F.S. (2014). Molecular and serological evaluation of Toxoplasma gondii infection in reared turkeys in Fars Province, Iran. Jundishapur Journal of Microbiology 7. https://doi.org/10.5812/jjm.11598

Schares, G., Vrhovec, M.G., Pantchev, N., Herrmann, D.C. \& Conraths, F.J. (2008). Occurrence of Toxoplasma gondii and Hammondia hammondi oocysts in the faeces of cats from Germany and other European countries. Veterinary Parasitology 152: 34-45. https://doi.org/10.1016/j.vetpar. 2007.12.004

Scheld, M.W., Marra, C.M., \& Whitley, R.J. (2014). Infections of the central nervous system. 4th edition. Philadelphia (USA): Lippincott Williams \& Wilkins.

Selseleh, M., Keshavarz, H., Mohebali, M., Shojaee, S., Selseleh, M., Eshragian, M.R., Mansouri, F. \& Modarressi, M.H. (2012). Production and evaluation of Toxoplasma gondii recombinant GRA7 for serodiagnosis of human infections. The Korean Journal of Parasitology 50: 233. https://doi.org/ 10.3347/kjp.2012.50.3.233

Shahbazi, G., Hoghooghi Rad, N., Madani, R., Matin, S., Mortazavi, P. \& Jangjou, A.H. (2019). Toxoplasma gondii in aborted fetuses of sheep in Ardebil area, north west of Iran. Iranian Journal of Parasitology 14: 430-435. https:// doi.org/10.18502/ijpa.v14i3.1482

Shuralev, E.A., Shamaev, N.D., Mukminov, M.N., Nagamune, K., Taniguchi, Y., Saito, T., Kitoh, K., Arleevskaya, M.I., Fedotova, A.Y., Abdulmanova, D.R. et al. (2018). Toxoplasma gondii seroprevalence in goats, cats and humans in Russia. Parasitology International 67: 112-114. https://doi.org/ 10.1016/j.parint.2017.10.014

Sibley, L.D. (2009). Development of forward genetics in Toxoplasma gondii. International Journal for Parasitology 39: 915-924. https://doi.org/10.1016/j.ijpara.2009.02.011

Singh, H., Tewari, A.K., Mishra, A.K., Maharana, B., Sudan, V., Raina, O.K. \& Rao, J.R. (2014). Detection of antibodies to Toxoplasma gondii in domesticated ruminants by recombinant truncated SAG2 enzyme-linked immunosorbent assay. Tropical Animal Health and Production 47: 171178. https://doi.org/10.1007/s11250-014-0703-5

Smith, N.C., Goulart, C., Hayward, J.A., Kupz, A., Miller, C.M. \& Dooren, G.G. (2021). Control of human toxoplasmosis. International Journal for Parasitology 51: 95-121. https:// doi.org/10.1016/j.ijpara.2020.11.001
Sonaimuthu, P., Fong, M.Y., Kalyanasundaram, R., Mahmud, R. \& Lau, Y.L. (2014). Sero-diagnostic evaluation of Toxoplasma gondii recombinant Rhoptry antigen 8 expressed in $E$. coli. Parasites \& Vectors 7: 297. https://doi.org/10.1186/1756-33057-297

Song, K.J., Yang, Z., Chong, C.K., Kim, J.S., Lee, K.C., Kim, T.S. \& Nam, H.W. (2013). A rapid diagnostic test for toxoplasmosis using recombinant antigenic $\mathrm{N}$ terminal half of SAG1 linked with intrinsically unstructured domain of GRA2 protein. The Korean Journal of Parasitology 51: 503. https:// doi.org/10.3347/kjp.2013.51.5.503

Sroka, J., Kusyk, P., Bilska-Zajác, E., Karamon, J., Dutkiewicz, J., Wójcik-Fatla, A., Zajác, V., Stojecki, K., Rózycki, M. \& Cencek, T. (2017). Seroprevalence of Toxoplasma gondii infection in goats from the south west region of Poland and the detection of $T$. gondii DNA in goat milk. Folia Parasitologica 64. https://doi.org/10.14411/fp.2017.023

Stavitsky, A.B. \& Jarchow, C.C. (1954). Micromethods for the study of proteins and antibodies: I. Procedure and general applications of hemagglutination and hemagglutination inhibition reactions with tannic acid and protein treated red blood cells. The Journal of Immunology 72: 360-367.

Stepick-Biek, P., Thulliez, P., Araujo, F.G. \& Remington, J.S. (1990). $19 \mathrm{~A}$ antibodies for diagnosis of acute congenital and acquired toxoplasmosis. Journal of Infectious Diseases 162: 270-273. https://doi.org/10.1093/infdis/162.1.270

Su, C., Shwab, E.K., Zhou, P., Zhu, X.Q. \& Dubey, J.P. (2010). Moving towards an integrated approach to molecular detection and identification of Toxoplasma gondii. Parasitology 137: 1-11. https://doi.org/10.1017/S0031182009991065

Su, C., Zhang, X. \& Dubey, J.P. (2006). Genotyping of Toxoplasma gondii by multilocus PCR-RFLP markers: A high resolution and simple method for identification of parasites. International Journal for Parasitology 36: 841-848. https:// doi.org/10.1016/j.ijpara.2006.03.003

Sudan, V., Tewari, A.K. \& Singh, H. (2019). Detection of antibodies against Toxoplasma gondii in indian cattle by recombinant SAG2 enzyme linked immunosorbent assay. Acta Parasitologica 64: 148-151. https://doi.org/10.2478/ s11686-018-00016-6

Sun, X., Lu, H., Jia, B., Chang, Z., Peng, S., Yin, J., Chen, Q. \& Jiang, N. (2013). A comparative study of Toxoplasma gondii seroprevalence in three healthy Chinese populations detected using native and recombinant antigens. Parasites \& Vectors 6: 241. https://doi.org/10.1186/1756-3305-6-241

Sun, X., Wang, Z., Li, J., Wei, F. \& Liu, Q. (2015). Evaluation of an indirect ELISA using recombinant granule antigen GRA1, GRA7 and soluble antigens for serodiagnosis of Toxoplasma gondii infection in chickens. Research in Veterinary Science 100: 161-164. https://doi.org/10.1016/ j.rvsc.2015.04.011

Sun, X.M., Ji, Y.S., Liu, X.Y., Xiang, M., He, G., Xie, L., Suo, J.X. \& Suo, X. (2017). Improvement and evaluation of loop mediated isothermal amplification for rapid detection of Toxoplasma gondii infection in human blood samples. PLOS ONE 12: e0169125. https://doi.org/10.1371/journal. pone.0169125

Suzuki, Y., Ramirez, R., Press, C., Li, S., Parmley, S., Thulliez, P. \& Remington, J.S. (2000). Detection of immunoglobulin M antibodies to P35 antigen of Toxoplasma gondii for serodiagnosis of recently acquired infection in pregnant women. Journal of Clinical Microbiology 38: 3967-3970. https:/ /doi.org/10.1128/jcm.38.11.3967-3970.2000 
Switaj, K., Master, A., Skrzypczak, M. \& Zaborowski, P. (2005). Recent trends in molecular diagnostics for Toxoplasma gondii infections. Clinical Microbiology and Infection 11: 170176. https://doi.org/10.1111/j.1469-0691.2004.01073.x

Talabani, H., Asseraf, M., Yera, H., Delair, E., Ancelle, T., Thulliez, P., Brézin, A.P. \& Dupouy-Camet, J. (2009). Contributions of immunoblotting, real time PCR, and the Goldmann Witmer coefficient to diagnosis of atypical toxoplasmic retinochoroiditis. Journal of Clinical Microbiology 47: 2131-2135. https://doi.org/10.1128/JCM.00128-09

Tassi, P. (2007). Toxoplasma gondii infection in horses. A review. Parassitologia 49: 7-15.

Tehrani, B.S., Mirzajani, E., Fallahi, S., Manouchehri Naeini, K., Mahmoudi, M.R., Safari Kavishahi, M., Eskandari, V. \& Zebardast, N. (2020). Challenging TaqMan probe-based real-time PCR and loop-mediated isothermal amplification (LAMP): the two sensitive molecular techniques for the detection of toxoplasmosis, a potentially dangerous opportunistic infection in immunocompromised patients. Archives of Microbiology 202: 1881-1888. https://doi.org/ 10.1007/s00203-020-01903-1

Teixeira, L.E., Kanunfre, K.A., Shimokawa, P.T., Targa, L.S., Rodrigues, J.C., Domingues, W., Yamamoto, L. \& Okay, T.S. (2013). The performance of four molecular methods for the laboratory diagnosis of congenital toxoplasmosis in amniotic fluid samples. Revista Da Sociedade Brasileira de Medicina Tropical 46: 584-588. https://doi.org/10.1590/00378682-0095-2013

Tenter, A.M., Heckeroth, A.R. \& Weiss, L.M. (2000). Toxoplasma gondii: from animals to humans. International Journal for Parasitology 30: 1217-1258. https://doi.org/10.1016/s00207519(00)00124-7

Tenter, A.M., Vietmeyer, C. \& Johnson, A.M. (1992). Development of ELISAs based on recombinant antigens for the detection of Toxoplasma gondii-specific antibodies in sheep and cats. Veterinary Parasitology 43: 189-201. https:/ /doi.org/10.1016/0304-4017(92)90160-B

Tenter, A.M., Vietmeyer, C., Johnson, A.M., Janitschke, K., Rommel, M. \& Lehmacher, W. (1994). ELISAs based on recombinant antigens for sero-epidemiological studies on Toxoplasma gondii infections in cats. Parasitology 109: 29-36. https://doi.org/10.1017/S0031182000077738

Terkawi, M.A., Kameyama, K., Rasul, N.H., Xuan, X. \& Nishikawa, Y. (2013). Development of an immunochromatographic assay based on dense granule protein 7 for serological detection of Toxoplasma gondii infection. Clinical and Vaccine Immunology 20: 596-601. https://doi.org/10.1128/CVI.0074712

Thiongo, S.K., Ichagichu, J.M., Ngotho, M., Aboge, G.O., Kagira, J.M., Karanja, S.M. \& Maina, N.N. (2016). Use of the nested polymerase chain reaction for detection of Toxoplasma gondii in slaughterhouse workers in Thika District, Kenya. South African Medical Journal 106: 417-419. https://doi.org/ 10.7196/SAMJ.2016.v106i4.8777

Tilahun, B., Tolossa, Y.H., Tilahun, G., Ashenafi, H. \& Shimelis, S. (2018). Seroprevalence and risk factors of Toxoplasma gondii infection among domestic ruminants in East Hararghe zone of Oromia Region, Ethiopia. Veterinary Medicine International 2018: 4263470. https://doi.org/ $10.1155 / 2018 / 4263470$

Tomasz, F.B., Holec-Gasior, L., Gatkowska, J., Dziadek, B., Dzitko, K., Grazlewska, W. \& Lautenbach, D. (2019). The first study on the usefulness of recombinant tetravalent chimeric proteins containing fragments of SAG2, GRA1, ROP1 and AMA1 antigens in the detection of specific antiToxoplasma gondii antibodies in mouse and human sera. PLOS ONE, 14: 1-23. https://doi.org/10.1371/journal.pone. 0217866
Tyebji, S., Hannan, A.J. \& Tonkin, C.J. (2020). Pathogenic Infection in Male Mice Changes Sperm Small RNA Profiles and Transgenerationally Alters Offspring Behavior. Cell Reports 31: 107573. https://doi.org/10.1016/j.celrep. 2020.107573

Udonsom, R., Buddhirongawatr, R. \& Sukthana, Y. (2010). Is sabin-feldman dye test using $T$. gondii tachyzoites from animal inoculation still the best method for detecting Toxoplasma gondii antibodies? Southeast Asian Journal of Tropical Medicine and Public Health 41: 1059-1064.

Udonsom, R., Popruk, S., Jirapattharasate, C., \& Mahittikorn, A. (2021). Recombinant Proteins as Antigens for Serological Detection of Toxoplasma gondii and Neospora caninum in Livestock. Journal of Applied Animal Science 14: 21-30.

Vielmo, A., Pena, H.F.J., Panziera, W., Bianchi, R.M., De-Lorenzo, C., Oliveira, S., Alves, B.F., Gennari, S.M., Pavarini, S.P. \& Barros, C.S.L. (2019). Outbreak of toxoplasmosis in a flock of domestic chickens (Gallus gallus domesticus) and guinea fowl (Numida meleagris). Parasitology Research 118: 991-997. https://doi.org/10.1007/s00436-019-06233-w

Vitale, M., Galluzzo, P., Currò, V., Gozdzik, K., Schillaci, D. \& Presti, V.D.M.L. (2013). A high sensitive nested PCR for Toxoplasma gondii detection in animal and food samples. Journal of Microbial and Biochemical Technology 5: 39-41. https://doi.org/10.4172/1948-5948.1000097

Vutova, K., Peicheva, Z., Popova, A., Markova, V., Mincheva, N. \& Todorov, T. (2002). Congenital toxoplasmosis: eye manifestations in infants and children. Annals of Tropical Paediatrics 22: 213-218. https://doi.org/10.1179/02724930 2125001507

Waldman, B.S., Schwarz, D., Wadsworth, M.H., Saeij, J.P., Shalek, A.K. \& Lourido, S. (2020). Identification of a master regulator of differentiation in toxoplasma. Cell 180: 359372.e16. https://doi.org/10.1016/j.cell.2019.12.013

Wana, M.N., Moklas, M.A.M., Watanabe, M., Nordin, N., Unyah, N.Z., Abdullahi, S.A., Alapid, A.A.I., Mustapha, T., Basir, R. \& Majid, R.A. (2020b). A review on the prevalence of Toxoplasma gondii in humans and animals reported in Malaysia from 2008-2018. International Journal of Environmental Research and Public Health 17: 4809 https:// doi.org/10.3390/ijerph17134809

Wana, M.N., Moklas, M.M.A., Watanabe, M., Unyah, N.Z., Abdullahi, S.A., Alapid, A.A.I., Nordin, N., Basir, R. \& Majid, A.R. (2020a). Molecular detection and genetic diversity of Toxoplasma gondii oocysts in cat faeces from Klang Valley, Malaysia, using B1 and REP genes in 2018. Pathogens 9: 576. https://doi.org/10.3390/pathogens 9070576

Wang, H., Lei, C., Li, J., Wu, Z., Shen, G. \& Yu, R. (2004). A piezoelectric immunoagglutination assay for Toxoplasma gondii antibodies using gold nanoparticles. Biosensors and Bioelectronics 19: 701-709. https://doi.org/10.1016/S09565663(03)00265-3

Wang, L., Chen, H., Liu, D., Huo, X., Gao, J., Song, X., Xu, X., Huang, K., Liu, W., Wang, Y. et al. (2013). Genotypes and mouse virulence of Toxoplasma gondii isolates from animals and humans in China. PLOS ONE 8: e53483. https:/ /doi.org/10.1371/journal.pone.0053483

Wang, Y., Wang, G., Ou, J., Yin, H. \& Zhang, D. (2014b). Analyzing and identifying novel B cell epitopes within Toxoplasma gondii GRA4. Parasites \& Vectors 7: 474. https://doi.org/ 10.1186/s13071-014-0474-x

Wang, Y.H., Li, X.R., Wang, G.X., Yin, H., Cai, X.P., Fu, B.Q. \& Zhang, D.L. (2011). Development of an immunochromatographic strip for the rapid detection of Toxoplasma gondii circulating antigens. Parasitology International 60: 105-107. https://doi.org/10.1016/j.parint. 2010.11.002 
Wang, Z., Ge, W., Li, J., Song, M., Sun, H., Wei, F. \& Liu, Q. (2014a). Production and evaluation of recombinant granule antigen protein GRA7 for serodiagnosis of Toxoplasma gondii infection in cattle. Foodborne Pathogens and Disease 11: 734-739. https://doi.org/10.1089/fpd. 2014.1749

Wassef, R. \& Abdel-Malek, R. (2019). Validity of a new immunochromatographic test in detection of Toxoplasma gondii in cancer patients. Journal of Parasitic Diseases 43: 83-86. https://dx.doi.org/10.1007\%2Fs12639-018-1063-2

Watson, G.F. \& Davis, P.H. (2019). Systematic review and meta analysis of variation in Toxoplasma gondii cyst burden in the murine model. In Experimental Parasitology 196: 55-62 https://doi.org/10.1016/j.exppara.2018.12.003

Webster, J.P. (2010). Review of "toxoplasmosis of animals and humans" by JP Dubey. Parasites \& Vectors 3: 112. https://doi.org/10.1186/1756-3305-3-112

Yan, C., Yue, C.L., Yuan, Z.G., Lin, R.Q., He, Y., Yin, C.C., Xu, M.J., Song, H.Q. \& Zhu, X.Q. (2010). Molecular and serological diagnosis of Toxoplasma gondii infection in experimentally infected chickens. Veterinary Parasitology 173: 179-183. https://doi.org/10.1016/j.vetpar.2010.07.011
Ybañez, R.H.D., Ybañez, A.P. \& Nishikawa, Y. (2020). Review on the current trends of toxoplasmosis serodiagnosis in humans. Frontiers in Cellular and Infection Microbiology 10: 204 https://doi.org/10.3389/fcimb.2020.00204

Zamora-Vélez, A., Triviño, J., Cuadrado-Ríos, S., Lora-Suarez, F. \& Gómez-Marín, J.E. (2020). Detection and genotypes of Toxoplasma gondii DNA in feces of domestic cats in Colombia. Parasite 27: 25 https://dx.doi.org/ 10.1051/ parasite $/ 2020023$

Zhang, X., Lowe, S.B. \& Gooding, J.J. (2014). Brief review of monitoring methods for loop mediated isothermal amplification (LAMP). Biosensors and Bioelectronics 61: 491499. https://doi.org/10.1016/j.bios.2014.05.039

Zhou, Y., Zhang, H., Cao, J., Gong, H. \& Zhou, J. (2013). Isolation and genotyping of Toxoplasma gondii from domestic rabbits in China to reveal the prevalence of type III strains. Veterinary Parasitology 193: 270-276. https://doi.org/10.1016/ j.vetpar.2012.11.031

Zhuo, X., Sun, H., Zhang, Z., Luo, J., Shan, Y. \& Du, A. (2017). Development and application of an indirect enzyme linked immunosorbent assay using recombinant MAG1 for serodiagnosis of Toxoplasma gondii in dogs. Journal of Parasitology 103: 237-242. https://doi.org/10.1645/16-89 